\title{
A cloud-based platform to predict wind pressure coefficients on buildings
}

\author{
Facundo Bre ( $\varangle)$, Juan M. Gimenez \\ Centro de Investigación de Métodos Computacionales (CIMEC), UNL, CONICET, Predio "Dr. Alberto Cassano", Colectora Ruta Nacional 168 s/n, \\ 3000, Santa Fe, Argentina
}

\begin{abstract}
Natural ventilation (NV) is a key passive strategy to design energy-efficient buildings and improve indoor air quality. Therefore, accurate modeling of the NV effects is a basic requirement to include this technique during the building design process. However, there is an important lack of wind pressure coefficients $\left(C_{p}\right)$ data, essential input parameters for NV models. Besides this, there are no simple but still reliable tools to predict $C_{p}$ data on buildings with arbitrary shapes and surrounding conditions, which means a significant limitation to NV modeling in real applications. For this reason, the present contribution proposes a novel cloud-based platform to predict wind pressure coefficients on buildings. The platform comprises a set of tools for performing fully unattended computational fluid dynamics (CFD) simulations of the atmospheric boundary layer and getting reliable $C_{p}$ data for actual scenarios. CFD-expert decisions throughout the entire workflow are implemented to automatize the generation of the computational domain, the meshing procedure, the solution stage, and the post-processing of the results. To evaluate the performance of the platform, an exhaustive validation against wind tunnel experimental data is carried out for a wide range of case studies. These include buildings with openings, balconies, irregular floor-plans, and surrounding urban environments. The $C_{p}$ results are in close agreement with experimental data, reducing $60 \%-77 \%$ the prediction error on the openings regarding the EnergyPlus software. The platform introduced shows being a reliable and practical $C_{p}$ data source for NV modeling in real building design scenarios.
\end{abstract}

\section{Keywords}

natural ventilation; building simulation; airflow network model; EnergyPlus; wind pressure coefficient; computational fluid dynamics

\section{Article History}

Received: 04 October 2021

Revised: 30 November 2021

Accepted: 20 December 2021

(C) Tsinghua University Press 2022

\section{Introduction}

In the last years, natural ventilation (NV) has gained increased attention in the seek for achieving energy-efficient building designs. This tendency is driven by the urgent need to decrease the emissions of gases that provoke the greenhouse effect and climate change. In particular, the building stock, including commercial, residential and public edifices, consumes $30 \%$ to $40 \%$ of the energy demanded worldwide, which means between $25 \%$ and $35 \%$ of the global $\mathrm{CO}_{2}$ emission (IEA 2016).

The naturally ventilated buildings can reduce the cooling energy consumption as much as $40 \%-75 \%$, concerning the air-conditioned buildings (Liu et al. 2014; Tong et al. 2016). Although the potential of the NV effects for several regions around the world has been validated (Sorgato et al. 2016; Tong et al. 2016; Chen et al. 2017), this phenomenon has been exploited mainly for residential buildings (Carrilho da Graça and Linden 2016). In the commercial sector, artificial air-conditioning keeps dominant through the use of heating, ventilation, and air-conditioning (HVAC) equipment, which represents about $51 \%$ of the energy used (Jung and Jazizadeh 2019). So, office buildings remain to be a great potential area to leverage the NV benefits. Especially in high-rise buildings, where wind-driven forces are less influenced by their surroundings as takes place in the low-rise ones (Tong et al. 2017).

Natural ventilation occurs when a pressure difference generated by natural forces, wind (wind-driven NV) and/or buoyancy forces (stack-driven NV), acts on one or more openings of the building envelope to induce airflows between the indoor and outdoor spaces. This exchange serves to supply and remove air mass through the building openings, and if the outdoor conditions are appropriate (e.g., the outside

E-mail: facubre@cimec.santafe-conicet.gov.ar 


\begin{tabular}{llll}
\multicolumn{2}{l}{ List of symbols } & \\
ABL & atmospheric boundary layer & CSV & comma-separated values format \\
ACH & air changes per hour & DOE & U.S. Department of Energy \\
AFN & airflow network model & HVAC & heating, ventilation, and air-conditioning \\
BIM & building information modeling & IDF & EnergyPlus input data file \\
BPS & building performance simulation & LES & large eddy simulation \\
BR & blockage ratio & NRMSE & normalized-root-mean-square error \\
CFD & computational fluid dynamics & NV & natural ventilation \\
CityGML & 3D city model file based on the & RANS & Reynolds averaged Navier-Stokes \\
& international open data standard & RMSE & root-mean-square error \\
$C_{p}$ & wind pressure coefficients & STL & standard triangle language file \\
$C_{p}$ & surface-averaged wind pressure coefficient & VTK & visualization toolkit file
\end{tabular}

temperature is lower than the inside one), a drastic cooling load reduction can be reached.

Because of the complex nature of wind-driven forces, designing naturally ventilated buildings and quantifying the actual effect of the NV for the typical local climate are challenging and difficult tasks (Ding and Lam 2019). This supposes a great limitation for the use of $\mathrm{NV}$ in real applications and discourages its implementation, since it represents a potential risk for building designers. To overcome this issue, the primary tool accepted for designing naturally ventilated buildings is the computational simulation (Sakiyama et al. 2020). In particular, computational fluid dynamics (CFD) is preferred when a high resolution of temporal and spatial indoor environment information is required. This tool has been used to simulate NV under a variety of conditions, including wind- and/or stack-driven flows (Zhai 2014). However, if measuring the NV impact along a typical climatic year is desired, CFD-based simulations are still unaffordable because of the computing time needed. This high computational effort is even greater whether alternative designs are being studied (e.g., varying the size and location of windows) or more complex optimization tasks involving additional architectural elements such as balconies, overhangs, are required.

Several reduced-order airflow models have been developed to quickly predict airflows through an entire building. Among these, the airflow network model (AFN) is the most reliable option for representing the $\mathrm{NV}$ phenomenon in complex geometries and general multi-zone buildings with several openings (Zhai et al. 2015). The AFN model proposed by $\mathrm{Gu}(2007)$ is widely used since it is implemented in the EnergyPlus software (Crawley et al. 2001), the most established software for building performance simulation (BPS).

Essential input data for AFN models and highly influential in the NV results are the wind-induced pressures on the building openings. This information is commonly characterized by the wind pressure coefficients $\left(C_{p}\right)$ (Cóstola et al. 2010). In BPS and AFN software, these data are incorporated in a simplified way through the surface-averaged value $\left(\overline{C_{p}}\right)$ per wind direction (Cóstola et al. 2009). To determine $\overline{C_{p}}$, most BPS-AFN programs make use of secondary data sources like databases (Orme and Leksmono 2002; ASHRAE 2009) or analytical models calibrated with experimental measurements (Swami and Chandra 1988; Grosso 1992; Muehleisen and Patrizi 2013; Bre et al. 2018). For instance, EnergyPlus uses by default the analytical equation proposed by Swami and Chandra (1988) to predict $\overline{C_{p}}$ on wall surfaces of low-rise buildings. However, the major drawback of secondary data sources is their low applicability to actual case studies, since they are mostly limited to isolated rectangular floor-plan buildings.

Given the high relevance of $C_{p}$ values as input data for AFN-BPS programs, a few attempts to develop specific tools to predict them have been made. The first effort was CpCalc, a parametric model developed by Grosso (1992) as an integrated module of the multi-zone airflow and contaminant transport model (COMIS) (Feustel 1999). CpCalc supposes an improvement regarding the Swami and Chandra model, since it predicts $C_{p}$ values at different surface locations and can consider the sheltering effects. Although the method was novel, its applicability is limited because of the lack of complete and high-quality experimental data to use in its development. This is a shortcoming recognized by the author himself (Grosso 1992). Another work with the same aim was performed in the $C_{p}$ Generator program. The last version (Knoll et al. 1997) also includes the prediction of the $C_{p}$ values at different surface locations, sheltering effects, and incorporates sloped roofs. However, its results show large deviations compared to the corresponding experimental data (same building, points locations, and wind directions) (Cóstola et al. 2009). Besides the aforementioned limitations, the usage of these two developments is constrained 
to only rectangular floor-plan buildings and cases studies within the spectrum of the database sources used to generate them. So, they cannot predict $C_{p}$ values for new building shapes, which seriously limits their use in real designs.

To overcome the drawback when the building has an arbitrary topology, a primary data source has to be used to get the $C_{p}$ values. A first option is to perform a wind tunnel experiment. However, this alternative is rarely employed by building design offices because of the economic cost and high know-how required. The second option comprises using a CFD-based approach, which has been recognized as a reliable tool (Cóstola et al. 2009; Ntinas et al. 2018; Zhang et al. 2020). Among the latest CFD contributions found in bibliography, Tominaga et al. (2015) used steady Reynoldsaveraged Navier-Stokes (RANS) simulations to investigate the airflow and mean wind pressures on isolated gable-roof buildings with different roof pitches. Gimenez et al. (2018) studied the performance of several RANS turbulence models to predict the $\overline{C_{p}}$ data on isolated low-rise buildings. Then, they used the best configuration to compute the $C_{p}$ data and analyzed the natural ventilation in a non-rectangular floor-plan building. Recently, Zheng et al. (2020) used steady RANS and large eddy simulation (LES) modeling to study the wind flow and mean surface pressure on buildings with balconies. Despite the advantages and reliable results of $\mathrm{CFD}$, it is hardly ever employed as an everyday design tool in technical offices to get $C_{p}$ data. This is because the CFD technique requires users of advanced expertise and access to high-performance computing resources.

To address the pinpointed limitations, this work introduces a new cloud-based platform to predict wind pressure coefficients on buildings. The core of the platform comprises a set of tools for performing unattended atmospheric boundary layer (ABL) simulations using CFD and getting $C_{p}$ data on buildings. This work aims to reach a dedicated and easy-to-use tool, where non-trained users can attain the results within an acceptable time frame. The novel platform offers reliable $C_{p}$ data for arbitrary building shapes and surrounding conditions. Advantages of not requiring either specialized hardware, with huge computational power and storage, or expensive software are gained thanks to the cloud-based approach.

Contributions throughout the entire CFD workflow are made. In pre-processing stage, a toolkit to construct the computational domain is developed. Here, the geometry of the target building and its surrounding, supplied through different input formats, is processed, reconstructed, and placed in a computational wind tunnel domain. Then, the resulting computational domain is automatically discretized. Regarding the processing stage, a series of ABL profiles for distinct terrain conditions are available, while3D steady Reynolds-averaged Navier-Stokes (RANS) simulations, including different RANS turbulence models, are used to compute the flow around buildings for a set of wind incidences. The post-processing stage comprises ad hoc tools for calculating detailed $C_{p}$ information ( $\overline{C_{p}}$ on building surfaces, $\overline{C_{p}}$ data on openings, point $C_{p}$ data, among others), and flow field information (pressure and velocities), which are exported in several output formats. Finally, to evaluate the robustness and accuracy of the developed tools, an exhaustive validation for a wide range of case studies is performed. The results attained are compared with wind tunnel experimental data and contrasted with $C_{p}$ estimations employed by the EnergyPlus software.

\section{Methodology}

\subsection{Platform overview}

The cloud-based platform aims to predict $C_{p}$ data on buildings, spanning from isolated structures to complex case studies that involve several buildings in an urban environment. The paradigm adopted, which comprises hosting a software service in a remote location that can be accessed and used from anywhere via Internet, strives to offer a powerful but easy-to-use tool. This approach enables users to access a dedicated computational tool, without requiring either specialized hardware (with huge computational power and storage space) or expensive software.

Figure 1 shows the working scheme of the proposed tools. The strengths of the platform are based on a set of tools for performing the entire CFD-based workflow for $\mathrm{ABL}$ simulations and getting $C_{p}$ data on buildings. These tools can be grouped into three main modules according to their application stage: pre-processing, processing and post-processing.

To request a set of desired $C_{p}$ data, the platform holds a web-based user interface ${ }^{1}$, which is implemented through modern web technologies (html5 + CSS + js) using responsive styles (i.e., design adaptable to different devices) to allow convenient, practical and cross-platform access from any type of device with an Internet connection. The request process only needs a few inputs, where the geometry of the target building and its surrounding is the main one. The geometry can be provided in different formats. Standard triangle language files (STL) are allowed because of their wide compatibility with most CAD software. EnergyPlus input data files (IDF) are supported to have compatibility with the most established software for BPS. The 3D city model files based on the international open data standard (CityGML), or its equivalent (CityJSON), can be also employed. This latter enables managing actual urban environments.

\footnotetext{
${ }^{1}$ https://cpsimulator.cimec.org.ar/
} 


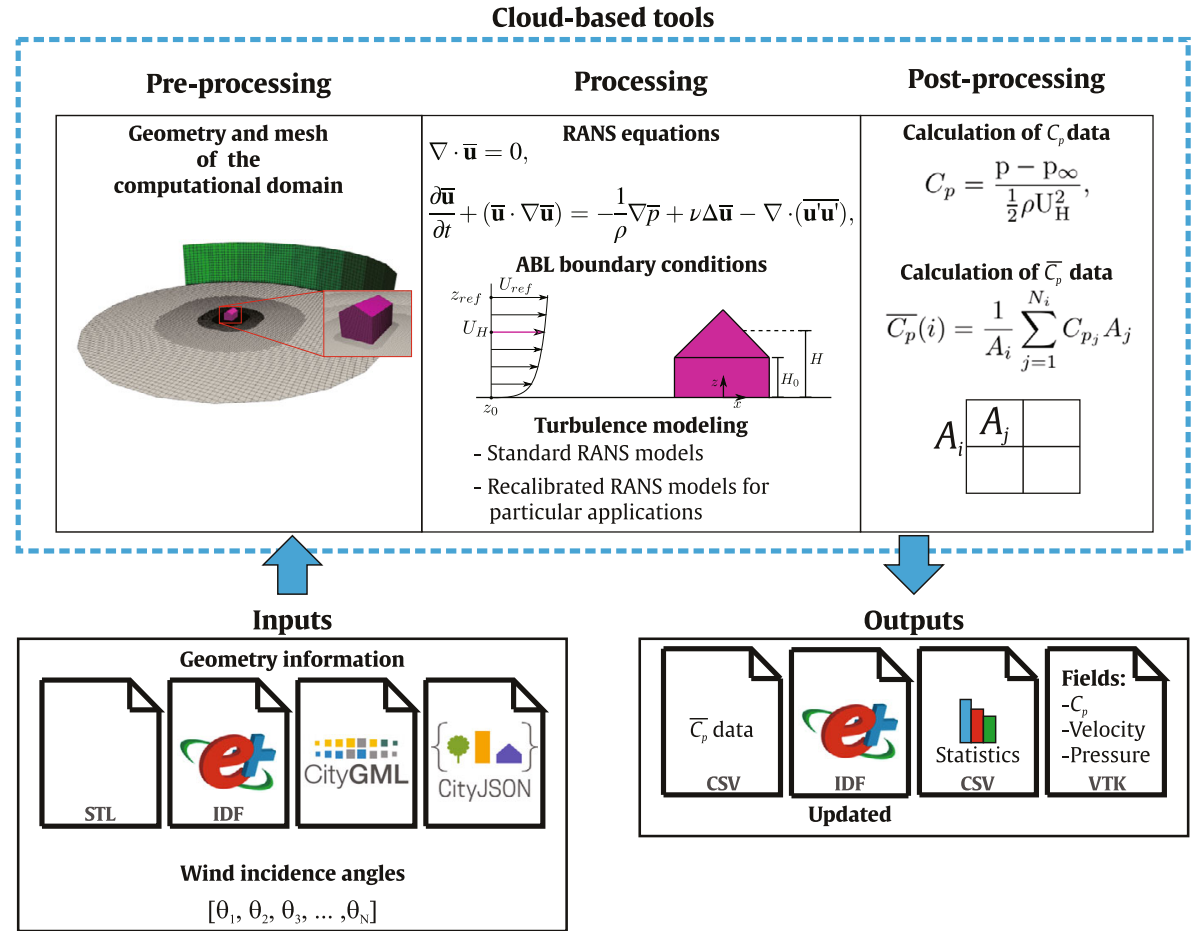

Fig. 1 Workflow and key components of the platform

Once executed the automatic procedure to attain the CFD results, the platform returns detailed $C_{p}$ data. This includes $\overline{C_{p}}$ on building surfaces, $\overline{C_{p}}$ data on openings, and point $C_{p}$ data. Also, flow field results as pressure and velocities are provided. The results are stored in a repository and accessed through a downloadable link. The main formats for the results are comma-separated values (CSV), Visualization Toolkit file (VTK), or EnergyPlus input data file (IDF). The latter is the same IDF file uploaded as input, which is updated with $C_{p}$ data in the associated AirflowNetwork model objects.

The features and operation of the developed cloud-based tools are detailed in the following section.

\subsection{Pre-processing}

The pre-processing stage involves a sequence of steps to reconstruct the target building and its environment and to generate the computational wind tunnel domain. Regarding the geometry model, it should accomplish a few basic requirements: (a) the building and its environment should be oriented such that the $+z$ coordinate determines the height direction and the $+y$ coordinate is aligned with the true North, (b) length units should be in meters, and (c) the building geometry should be split into different surfaces according to their usage (e.g., walls, roofs, floors, windows, etc.). Figure 2 shows an example of the geometry references.

To provide a straightforward way for most of the BPS community, the platform supports as input geometry format

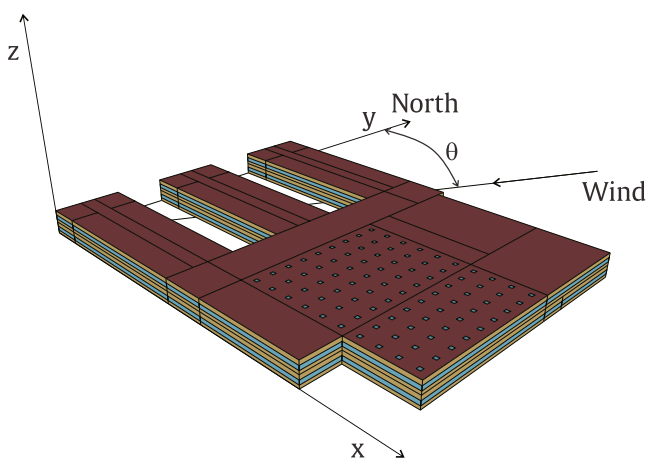

Fig. 2 Example of the geometry references for a prototype building model (Secondary School) developed by DOE (2021)

the same IDF file employed for BPS through EnergyPlus (Crawley et al. 2001). Therefore, all the buildings described in the IDF, which can have one or multiple thermal zones, are considered in the pre-processing stage. Figure 3 summarizes the pre-processing workflow for the IDF format.

The pre-processing module has other particular features for this input format. For instance, if there are openings described in the IDF, these are processed as separated surfaces to compute the $\overline{C_{p}}$ on each one. $\overline{C_{p}}$ in openings is the most detailed information that can be provided in the airflow network model. Also, shading objects are interpreted as surfaces without thickness for the CFD simulations. This feature easily allows including several architectural elements of interest like balconies, overhangs, shadings, among others.

The first action of the pre-processing stage is reading 


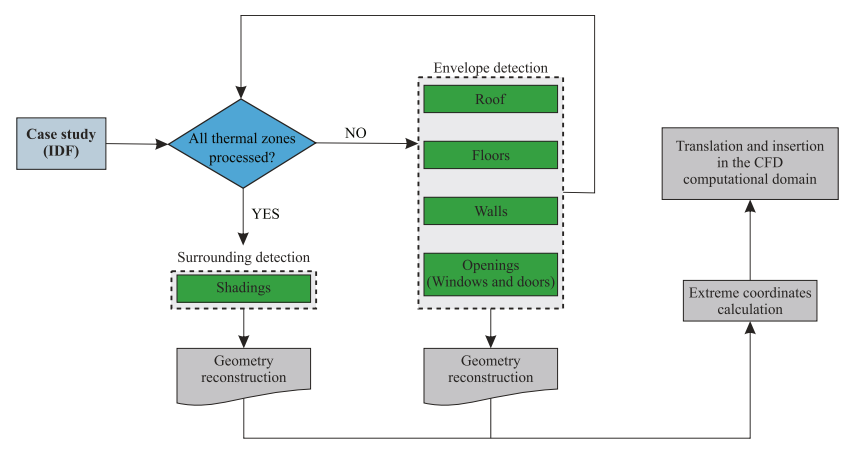

Fig. 3 Pre-processing workflow for IDF files. An iterative procedure detects the components of the geometry, reconstructs and places them in the CFD computational domain

the input geometry from one of the input formats introduced before, and computing its extreme coordinates $\mathrm{EC}=\left[\left(x_{\min }\right.\right.$, $\left.\left.y_{\min }, z_{\min }\right),\left(x_{\max }, y_{\max }, z_{\max }\right)\right]$. Then, the original geometry is moved by the translation operation $\left[-\left(x_{\max }-x_{\min }\right) / 2,-\left(y_{\max }\right.\right.$ $\left.\left.-y_{\min }\right) / 2\right]$ such that the center of coordinates is placed at the centroid of the buildings at ground level. Therefore, the geometry is introduced in a computational wind tunnel domain with a coincident center of coordinates, whose shape, dimensions, and meshing strategy are discussed below.

\subsubsection{Computational domain definition}

To perform the ABL simulations for different wind incidence angles reusing the same mesh, the platform employs a particular geometry shape for the computational wind tunnel domain (see Figure 4). A regular polygon of $P$ sides represents the external limit of the domain, being $P=24$, the default configuration. This feature gives the possibility of setting inflow or outflow boundary conditions for any wind incidence direction while reduces the total size of the computational domain. This kind of wind tunnel shape has several advantages, which are even more noticeable in problems where at least eight wind directions have to be studied, as was recently shown by Kastner and Dogan (2020). The platform simulates and predicts $C_{p}$ data for at least 12 wind directions, exploiting enough such advantages.

Regarding the dimensions of the computational domain, the ones advised by the European best practice guidelines of COST Action 732 are met (Franke et al. 2007). These guidelines suggest the minimum distances between the building or urban model and the boundaries of the domain, and also the maximum allowed blockage ratio for typical box-shape wind tunnels. Being $H_{\text {building the height of the }}$ tallest building of the model, the inlet, the lateral and top boundary should be at least $5 H_{\text {building }}$ away from the target geometry (building or set of buildings). Besides, the outflow boundary should be at least $15 H_{\text {building }}$ away from the target geometry to guarantee a full development of the wake flow. The blockage ratio (BR), which is defined as the ratio of the projected frontal (windward) area of the obstacles ( $\left.A_{\text {building }}\right)$ and the cross-section of the computational domain $\left(A_{\text {domain }}\right)$ (Barlow et al. 1999), should be less than $3 \%$. This is,

$$
\mathrm{BR}=100 \% \frac{A_{\text {building }}}{A_{\text {domain }}} \leq 3 \%
$$

Given the particular shape of the computational wind tunnel domain proposed to reuse the same mesh for different wind incidence directions, these limits for the domain size have to be adapted. Figure 4 shows the reference dimensions considered. As mentioned before, the geometry of the target building or urban environment is centered in the wind tunnel domain, resulting in similar extensions for the windward, leeward, and lateral flow spaces, see Figure 4(a). Therefore, to accomplish the COST requirements for any wind incidence direction, the minimal distance between the building (or urban) and any side of the boundary has to satisfy the most critical one, which is the outflow distance $\left(W_{\text {outflow }}\right)$ of at least $15 H_{\text {building. }}$

In some particular cases like urban low-rise buildings (see Figure 4(a)), depending on the value of $H_{\text {domain }}$, the BR cannot be guaranteed. So, a new directional blockage ratio for wind tunnels with cylindrical or similar shapes is derived. This is based on the recommendation of Blocken (2015) for box-shape wind tunnel domains that define the BR for the vertical and horizontal dimensions respectively, as:

$$
\begin{aligned}
& \mathrm{BR}_{\mathrm{V}}=100 \% \frac{H_{\text {building }}}{H_{\text {domain }}} \leq 17 \% \\
& \mathrm{BR}_{\mathrm{H}}=100 \% \frac{W_{\text {building }}}{W_{\text {domain }}} \leq 17 \%
\end{aligned}
$$

where $W_{\text {domain }}$ is the width of the domain and $W_{\text {building }}$ is the maximum projected frontal width of the building (or urban envelope), herein for any wind incidence, see Figure 4(a).

Using these criteria simultaneously, a $\mathrm{BR} \leq 3 \%$ is guaranteed and a negligible virtual acceleration is achieved in both top and lateral regions of the modeled building. Finally, combining these conditions with the minimal outflow distance, the domain dimensions are defined as,

$$
\frac{H_{\text {domain }}}{H_{\text {building }}}=6
$$

where Eq. (4) guarantees the vertical blockage ratio of Eq. (2), and

$$
W_{\text {outllow }}=\max \left(15 H_{\text {building }}, 2.5 W_{\text {building }}\right)
$$

where the first term, $15 H_{\text {building, guarantees the minimal }}$ distance to get full development of wake flow, and the second

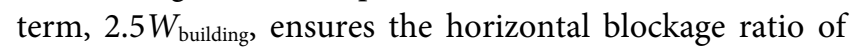
Eq. (3). 


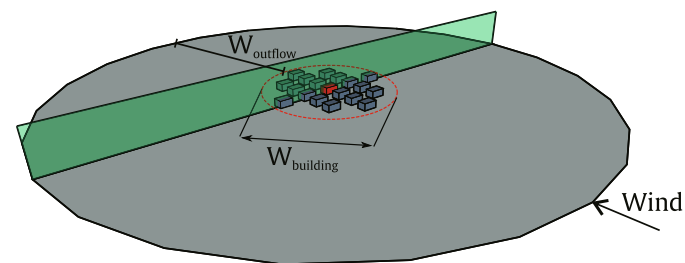

(a)

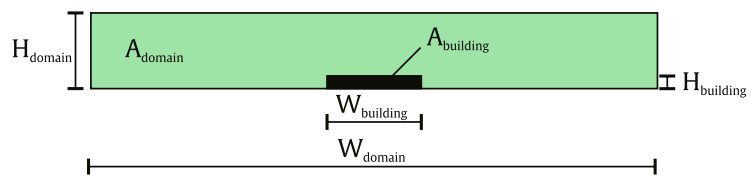

(b)

Fig. 4 Computational domain for the CFD-based simulations: (a) the 3D perspective of the resulting computational domain for a case study of a generic urban area; (b) reference dimensions

\subsubsection{Discretization}

Once the computational domain is determined, the meshing module generates the mesh. Because this module is based on the snappyHexMesh tool (Fabritius and Tabor 2016; OpenFOAM 2021), the procedure comprises three stages. First, the surfaces that define the buildings and the boundaries of the computational domain are shaped by recursive refinements of a background hexahedral mesh. Second, a morphing stage fits the mesh to the surfaces, getting split-hex cells around the objects. The final stage shrinks back the mesh and inserts prismatic cell layers over the building surfaces. The entire process is an automated strategy suitable even for complex buildings and urban environments regardless of their alignment, but is controlled by several parameters set in advance.

A key stage on the platform is to define the meshing specification automatically. This includes setting the reference cell size of the background mesh, the refinement levels at the surfaces and inside predetermined volumetric regions, and the mesh quality requirements. For this purpose, automated analysis of the envelope of the target building and its surroundings to get the geometry reference lengths is performed. The reference cell size and the refinement level at the building surfaces are chosen to guarantee at least 20 cells per direction (Tominaga et al. 2008) on the shortest building side. With non-convex floor-plane shapes as C-shape and L-shape buildings, the refinement level is increased based on the characteristic length of the concavity detected. To guarantee that grid lines are perpendicular to the wall and correctly reproduce the flow separation, four prismatic cells layers are placed on every surface of the target building, increasing the thickness of each successive layer with an expansion ratio of two, see Figure 5(a).

Also, volumetric refinement levels according to the distance to the buildings are defined. This setting allows the

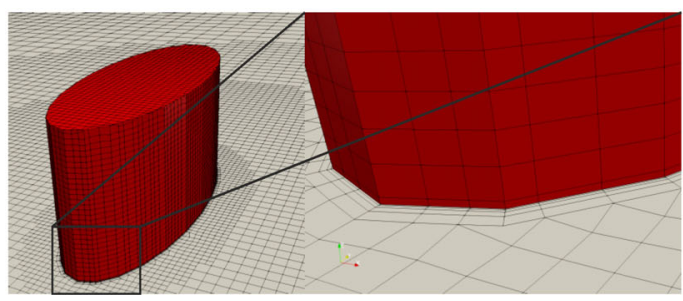

(a)

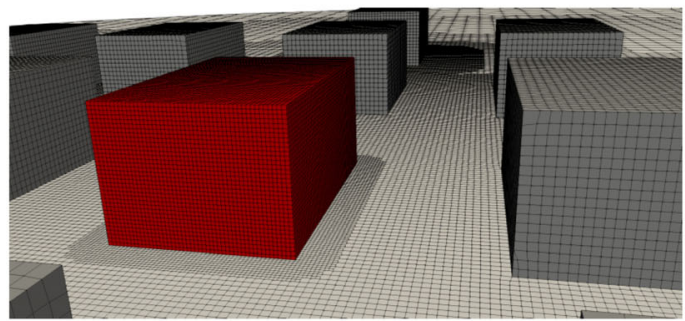

(b)

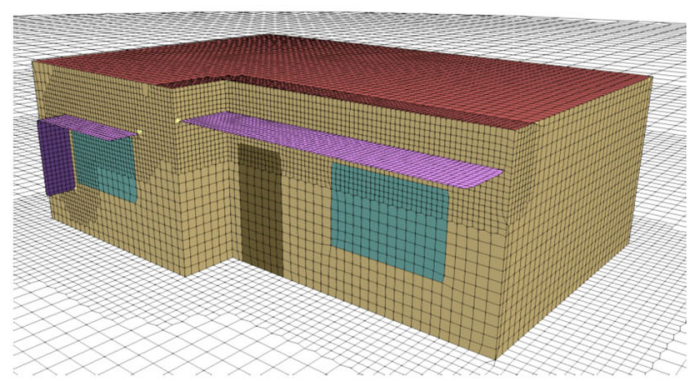

(c)

Fig. 5 Details of automatic mesh refinements: (a) detail of the cell layers next to the building surfaces; (b) detail of the volume and the surface refinements for multi-building configurations with a target building; (c) detail of the refinements on baffles surfaces.

grid to capture physical phenomena like shear layers and vortical structures. With urban environments, a one-lowerlevel of refinement of surrounding buildings and the ground among them is applied. Because of the aforementioned refinements, a proper number of cells is guaranteed between buildings (canyons) (Franke et al. 2004), see Figure 5(b), as well as between opposite surfaces belonging to the same building.

Thinner elements over surfaces, such as balconies and shadings, are considered baffles. This is, the internal faces that represent these thin walls are treated as boundary faces. Extra refinement levels can be set on these kinds of elements to depict their geometric features properly, see Figure 5(c). Finally, to avoid high grown ratios at any location of the mesh, eight cells are required as buffer layers between successive refinement levels.

The quality of the computational cells is controlled through the maximum skewness ( 4 on internal faces and 20 on boundary faces), the maximum non-orthogonality (70 degrees), and the minimum volume ratio between each tetrahedron and its circumscribed sphere (0.01) parameters. 
The meshing procedure prioritizes these requirements over a strict conforming of any detail of the geometry. The resulting high-quality hex-dominant mesh is well suited for the finite volume method because of the low truncation errors and the fast iterative convergence (Blocken 2015).

The meshes obtained by this automatic configuration, which fulfill the state-of-art guidelines, were analyzed against successive refinements varying the reference size of the background grid, see Appendix A, which is available in the Electronic Supplementary Material of the online version of this paper.

\subsection{Processing}

Regarding the use of CFD simulations in ABL applications, there are two main numerical approaches to solve the turbulent flow governed by the Navier-Stokes equations: large eddy simulation (LES) modeling and Reynolds-averaged Navier-Stokes (RANS) modeling (Blocken 2018).

It is well known that the LES approach is intrinsically superior in terms of physical modeling to the RANS one. However, the RANS approach has been shown as a reliable option in several industrial and research applications (Blocken 2015; Toparlar et al. 2017; Blocken 2018). This virtuous performance led it to be a standard for simulation of flows in urban environments (Franke et al. 2007; Tominaga et al. 2008).

The computational cost of LES-based simulations is at least an order of magnitude larger than for steady RANS. Additionally, this effort grows proportionally with the number of wind directions to be analyzed. So, given the aim of providing reliable $C_{p}$ data results within an acceptable time frame for building designers, the RANS approach is adopted and implemented in this work, as described below.

\subsubsection{RANS modeling approach}

The ABL flow is considered as an incompressible homogeneous viscous fluid flow with constant density $\rho$ and kinematic viscosity $v$. RANS modeling approach comprises the Reynolds decomposition of the fields of the Navier-Stokes equations. This is, the velocity $\mathbf{u}$ and pressure $p$ are split into its mean value (time-averaged or ensemble-averaged) and fluctuating parts. For instance, $\mathbf{u}=\overline{\mathbf{u}}+\mathbf{u}^{\prime}$, where $\overline{\mathbf{u}}$ is the mean value and $\mathbf{u}^{\prime}$ the fluctuating part. Hence, by applying this decomposition to variables of the Navier-Stokes equations ( $\left.\mathbf{u}=\overline{\mathbf{u}}+\mathbf{u}^{\prime}, p=\bar{p}+p^{\prime}\right)$ and averaging, leads to the Reynolds averaged Navier-Stokes (RANS) equations (Ferziger and Peric 2002), which are described as:

$$
\begin{aligned}
& \nabla \cdot \overline{\mathbf{u}}=0 \\
& \frac{\partial \overline{\mathbf{u}}}{\partial t}+(\overline{\mathbf{u}} \cdot \nabla \overline{\mathbf{u}})=-\frac{1}{\rho} \nabla \bar{p}+v \Delta \overline{\mathbf{u}}-\nabla \cdot\left(\overline{\mathbf{u}^{\prime} \mathbf{u}^{\prime}}\right)
\end{aligned}
$$

where the unknowns are the mean velocity field $\overline{\mathbf{u}}$ and the mean pressure field $\bar{p}$.

RANS turbulence modeling Most of RANS models assume that the fluctuating part $\mathbf{u}^{\prime}$ obey the Boussinesq hypothesis, such that,

$$
\overline{\mathbf{u}^{\prime} \mathbf{u}^{\prime}}=v_{\mathrm{t}} \nabla^{\mathrm{S}} \overline{\mathbf{u}}
$$

where $v_{\mathrm{t}}$ is the eddy viscosity and $\nabla^{\mathrm{S}}$ is the symmetric gradient operator.

Several RANS models have been developed over years for general applications (Jones and Launder 1972; Spalart and Allmaras 1992; Yakhot et al. 1992; Menter 1994; Shih et al. 1995). Most of them are based on solving transport equations for turbulent variables to determine the value of $v_{\text {t. }}$ The standard $k-\varepsilon$ model cannot reproduce the separation and reverse flow on the rooftop of a building because of its overestimation of turbulence energy in the impinging region of the building wall. Given these well-known problems, the best practice guidelines conclude it should not be used in wind engineering simulations (Franke et al. 2004, 2007; Tominaga et al. 2008). Some alternative models to improve this particular aspect have been developed (Kato and Launder 1993; Tsuchiya et al. 1997). However, its application did not become extensive since the improvements were not significant or other desired features of the original model were lost.

From the revised versions of $k-\varepsilon$ model, the platform employs by default the renormalization group (RNG) $k-\varepsilon$ model (Yakhot et al. 1992) for low-rise buildings and the $k$ - $\omega$ SST model (Menter 1994) for high-rise buildings. Based on our experience and other research references (Tominaga et al. 2015; Tominaga 2015; Toparlar et al. 2017), the employed models are the options with the best agreement with experimental wind tunnel data for ABL applications. Alternatively, there are also available the realizable $k-\varepsilon$ model (Shih et al. 1995), and optimized RANS models. These latter were recalibrated for ABL simulations aiming to improve the $C_{p}$ prediction on specific buildings typologies and surrounding conditions (Gimenez and Bre 2019).

\subsubsection{Boundary conditions}

Given the particular shape of the computational domain used, the boundary conditions at the planes of the external bounds are changed according to the wind incidence analyzed. This is made by comparing the orientation of the normal vector to the surface, say $\mathbf{n}$, with the current wind velocity $\mathbf{u}_{\text {in }}$. Hence, if $\mathbf{u}_{\text {in }} \cdot \mathbf{n}>0$, the boundary is an outflow patch (zero static pressure). The boundary is prescribed as a symmetry plane, i.e., zero normal velocity and zero normal gradients of all variables if $\mathbf{u}_{\text {in }} \cdot \mathbf{n}=0$ (i.e., $\mathbf{u}_{\text {in }}$ perpendicular to $\mathbf{n}$ ). An inlet boundary condition is imposed if $\mathbf{u}_{\text {in }} \cdot \mathbf{n}<0$.

The wind incidence angle is defined as 
$\theta=\operatorname{acos}\left(-\mathbf{j} \cdot \mathbf{u}_{\text {in }} /\left|\mathbf{u}_{\text {in }}\right|\right)$, where $\mathbf{j}$ is the $y$-coordinate versor. This means that zero angle $\theta=0^{\circ}$ is defined when the wind flow is coming from the $+y$ direction, which is the north direction under our guidelines to provide the geometry. Incidence angles are then altered following a clockwise rotation.

For the inlet boundary conditions, the approaching wind profile for a neutral ABL is modeled using boundary conditions suggested by Richards and Hoxey (1993), being the inflow velocity defined as:

$$
\left|\mathbf{u}_{\mathrm{in}}\right|=\frac{U_{\mathrm{ABL}}^{*}}{\kappa} \ln \left(\frac{z+z_{0}}{z_{0}}\right)
$$

where $U_{\mathrm{ABL}}^{*}$ is the friction velocity, $\kappa=0.41$ is the von Karman's constant, $z$ is the vertical coordinate $(\mathrm{m})$, and $z_{0}$ is the aerodynamic roughness height $(\mathrm{m})$.

The kinetic energy, $k$, and turbulence dissipation rate, $\varepsilon$, inlet profiles are defined as:

$$
\begin{aligned}
& k=\frac{U_{\mathrm{ABL}}^{*}{ }^{2}}{\sqrt{C_{\mu}}} \\
& \varepsilon=\frac{U_{\mathrm{ABL}}^{*}{ }^{3}}{\kappa\left(z+z_{0}\right)}
\end{aligned}
$$

where $C_{\mu}=0.09$ is the turbulent viscosity coefficient.

The friction velocity is estimated as:

$$
U_{\mathrm{ABL}}^{*}=\kappa \frac{U_{\text {ref }}}{\ln \left(\left(z_{\text {ref }}+z_{0}\right) / z_{0}\right)}
$$

where $U_{\text {ref }}$ is the reference velocity $(\mathrm{m} / \mathrm{s})$ at the reference height given $z_{\text {ref }}(\mathrm{m})$.

Therefore, to model an inlet velocity profile based on the log-law through Eqs. (9) and (11), the values of $U_{\text {ref, }} z_{\text {ref, }}$ and $z_{0}$ have to be defined. So, the platform offers four optional modules: (1) Log-law, (2) Terrain classification, (3) Auto-fitting, and (4) Power-law.

Using the first option, Log-law, the users should supply the three values for $U_{\text {ref, }}, z_{\text {ref, }}$ and $z_{0}$ to customize the wind speed profile for their particular analysis. Values of $U_{\text {ref }}$ ranging $10-50 \mathrm{~m} / \mathrm{s}$ at $z_{\text {ref }}=200$ to $600 \mathrm{~m}$ (velocity at gradient height) are satisfactory, while to select the $z_{0}$ value is recommended to follow the roughness classification proposed by Wieringa (1992). The second alternative, Terrain classification, provides four discrete options to configure the ABL profile in practical applications. Table 1 reports the parameter values used for each choice.

Sometimes the users can desire to employ a power-law or measured data at different heights that cannot be easily related to a log-law within the options of the parameter values given above. So, to overcome this, the Auto-fitting and the Power-law options are also available.
Table 1 Discrete terrain classification

\begin{tabular}{lccc}
\hline \multicolumn{1}{c}{ Case } & $z_{0}[\mathrm{~m}]$ & $z_{\text {ref }}[\mathrm{m}]$ & $U_{\text {ref }}[\mathrm{m} / \mathrm{s}]$ \\
\hline 1. Very flat terrain & 0.0025 & 250 & 40 \\
2. Open country & 0.025 & 350 & 40 \\
3. Suburban & 0.25 & 450 & 40 \\
4. Urban & 2.5 & 550 & 40 \\
\hline
\end{tabular}

In the first one, the users should provide a set of velocity values at different heights through a two-column CSV file. Using these values, an automatic fitting procedure based on numerical optimization is performed to determinate the configuration of the $U_{\text {ref }}, z_{\text {ref }}$, and $z_{0}$ which best agrees with the input data.

In the Power-law module, the users should provide the three-parameter values, $U_{s}, z_{s}$, and $\alpha$, which define the ABL profile as:

$\left|\mathbf{u}_{\text {in }}\right|=U_{s}\left(\frac{z}{z_{\mathrm{s}}}\right)^{\alpha}$

Then, an automatic fitting procedure is employed to determinate the configuration of $U_{\text {ref, }}, z_{\text {ref, }}$ and $z_{0}$ of Eqs. (9) and (11) that best agree with the desired power-law within the limits of the domain, i.e. $0 \leq z_{\text {ref }} \leq H_{\text {domain }}$.

A critical requirement is to guarantee that the inflow ABL profile imposed preserves its shape throughout the upstream domain despite the distance from the inlet to the building, i.e. maintains the horizontal homogeneity. Therefore, a compatible wall function on the ground is applied along with a fixed shear stress condition on the top $\left(\tau_{\text {top }}\right)$ boundary of the domain (Heargraves and Wright 2007). This latter is defined as:

$\tau_{\text {top }}=\rho U_{\mathrm{ABL}}^{*}{ }^{2}$

and the wall function at the ground, which also considers its roughness, estimates the wall shear stress $\tau_{\text {ground }}$ as:

$\tau_{\text {ground }}=\frac{\rho \kappa C_{\mu}^{1 / 4} k_{\mathrm{c}}^{1 / 2}\left|\mathbf{u}_{\mathrm{c}}\right|}{\ln \left(\left(z_{\mathrm{c}}+z_{0}\right) / z_{0}\right)}$

where the subscript $c$ refers to the cell next to the ground, and $z_{\mathrm{c}}$ is the normal distance from the ground to this cell center.

Regarding building surfaces, these are modeled as smooth surfaces and a non-slip condition for the velocity is imposed on them. Hybrid wall functions are used for turbulent variables. These models provide boundary conditions that adapt to the location of the first cell center. The particular implementation used in this work is described in Liu (2016).

In conclusion, Table 2 summarizes the boundary conditions employed by the platform. 
Table 2 Summary of the boundary conditions employed

\begin{tabular}{cccc}
\hline Location & Velocity & Pressure & Turbulent variables \\
\hline Inlet & $\begin{array}{c}\text { ABL profile }- \\
\text { Eq. (9) }\end{array}$ & Zero-gradient & ABL profiles - Eqs. (10) \\
\hline Outlet & Outflow & Outflow & Outflow \\
Ground & $\begin{array}{c}\text { No-slip } \\
\text { Zero-gradient }\end{array}$ & ABL wall functions - Eq. (14) \\
Top & $\begin{array}{c}\text { Shear stress - } \\
\text { Eq. (13) }\end{array}$ & Zero-gradient & Zero-gradient \\
$\begin{array}{c}\text { Building } \\
\text { walls }\end{array}$ & No-slip & Zero-gradient & $\begin{array}{c}\text { Hybrid wall functions (Liu et al. } \\
\text { 2016) }\end{array}$ \\
\hline
\end{tabular}

\subsubsection{Solver settings}

The time-averaged RANS equations are solved using an implicit, segregated, three-dimensional finite volume method (FVM). Pressure-velocity coupling is solved with the SIMPLE algorithm (Ferziger and Peric 2002) by using the implementation available in the open-source software OpenFOAM. The running procedure starts the simulation with velocity and turbulent fields initialized everywhere to the free-stream conditions. At the beginning, first-order schemes for the convective and viscous terms of the RANS equations along with under relaxation are employed to guarantee stability. After the initial 500 iterations, the relaxation is gradually deactivated. Then, the spatial and time discretization schemes are switched to second-order to avoid numerical/artificial diffusion (Blocken 2015). The iterative solving process continues until the normalized residuals for continuity, velocity components, and turbulent fields have decreased by five orders of magnitude each one.

\subsubsection{Parallelization}

To achieve a reliable description of the $C_{p}$ behavior regarding the incoming flow direction, the default configuration evaluates 12 wind incidence angles (every 30 degrees). This means solving 12 steady-state CFD simulations. The computing time per simulation is about five core hours per million elements, leading to a total requirement of about 40 core hours for typical isolated buildings, and at least 200 core hours in typical urban environments. Therefore, to respond within a reasonable window time of design, the automated processing of a request for $C_{p}$ data is executed in an HPC cluster (Seshat 2020) employing a two-level parallelization scheme. First, a task parallelization level is implemented, where an internal queuing system distributes the individual simulations to available idle nodes. Second, each simulation runs in parallel using the computing cores available in the assigned node. This latter requires the partition of the computational domain, which is also an unattended process implemented on the platform. Finally, the global queuing system of the cluster manages the execution of the simultaneous requests.

\subsection{Post-processing}

Once the numerical solutions for each wind direction requested are reached, automated post-processing is carried out to calculate detailed $C_{p}$ data.

The $C_{p}$ at any point of the façade is defined as the dimensionless ratio between the dynamic pressure at that point and the dynamic pressure of the airflow (wind) in the freestream. Mathematically, it is expressed as,

$C_{p}=\frac{p-p_{\infty}}{\frac{1}{2} \rho U_{H}^{2}}$

where $p$ is the static pressure $(\mathrm{Pa})$ at a point of façade and $p_{\infty}$ is the static reference pressure $(\mathrm{Pa})$ at freestream (i.e., far away from any disturbance), which is taken as $0 \mathrm{~Pa}$ by default.

The term $\frac{1}{2} \rho U_{H}^{2}$ is the dynamic pressure (Pa), where $\rho$ is the air density and $U_{H}$ is the freestream wind speed, which is taken at the building mean roof height $H$ in the upstream undisturbed flow, see Figure 6.

Once the $C_{p}$ field is calculated, the averaged pressure coefficient $\left(\overline{C_{p}}\right)$ on each building surface $i$ (wall, roof, opening) can be derived. When using FVM, $C_{p}$ are discrete values associated with the centroid of each internal element (cell) or boundary element (face). So, the $\overline{C_{p}}$ for a building surface $i$ is calculated as,

$\overline{C_{p}}(i)=\frac{1}{A_{i}} \sum_{j=1}^{N_{i}} C_{p_{j}} A_{j}$

where $C_{p_{j}}$ is the pressure coefficient computed in $j$-th face, with area $A_{j}$, on the target surface $i$, being $N_{i}$ the number of surface faces on the target surface $i$, and $A_{i}=\sum_{j=1}^{N_{i}} A_{j}$, the area of the target surface $i$.

After automatically carry out this post-processing stage for each wind incidence simulated, the output results are returned to the user.

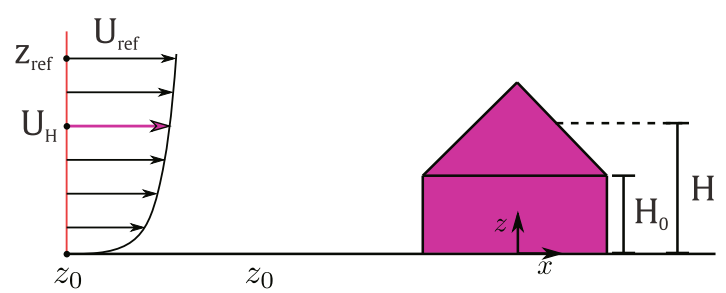

Fig. 6 Reference values employed to calculate the $C_{p}$ and $\overline{C_{p}}$ data

\section{Case studies}

This section aims to present a comprehensive validation of the tools and the capabilities for a wide range of case 
studies. To achieve this, the numerical solutions obtained via the automatic procedure described above are compared with experimental wind tunnel data.

Most of the experimental data are taken from the windtunnel measurements performed by the Wind Engineering Information Center of Tokyo Polytechnic University (TPU 2021), but also there are results got from other experimental studies. Simultaneously, the $C_{p}$ data commonly employed by most building designers through EnergyPlus are also computed and compared to show the hidden inaccuracies when using these models, even for simple building shapes.

The input geometries and the output results derived from the case studies analyzed are provided in Bre and Gimenez (2021) for a closer analysis or its reproduction.

\section{1 $\overline{C_{p}}$ in openings}

The first validation case aims to evaluate the capabilities of the automatic cloud-based tools to predict the $\overline{C_{p}}$ on the building openings.

A set of wind tunnel results for an isolated low-rise building ${ }^{2}$ available in the TPU database (TPU 2021) is chosen. The building has a depth-to-breadth ratio $D / B=$ $3 / 2$ and a height-to-breadth ratio $H / B=1 / 4$, being $B=$ $16 \mathrm{~m}, D=24 \mathrm{~m}$, and $H=4 \mathrm{~m}$. The length scale for the TPU database experiments was set at 1:100. The 384 wind pressure measurement taps were disposed uniformly over the surfaces of the tested models. Basic spaces among the taps were $20 \mathrm{~mm}$, corresponding to $2 \mathrm{~m}$ at full scale. In every case presented in this work, breadth is measured on the surface that is orthogonal to the wind direction when the incidence angle $\theta=0^{\circ}$. Figure 7 (a) shows the geometry of the case study generated in an IDF file, including the dimension references. The mesh generated this case study has almost $650 \mathrm{~K}$ polyhedral cells, where $97 \%$ of them are hexahedra, see Figure 7(b).

Three rectangular windows (Win-1, Win-2, and Win-3) of height $=2 \mathrm{~m}$ and breadth $=5 \mathrm{~m}$ are placed on Surf- 2 . They are centered at both height and width, with a horizontal separation of $8 \mathrm{~m}$ between their vertical axes. As exposed in the method section, these three windows are recognized by the platform-tools since they are defined as fenestration surfaces in the IDF. So, separated boundary surfaces are generated to compute $\overline{C_{p}}$ on each one of them. The latter enables generating the corresponding AirflowNetwork objects during the post-processing process.

The wind profile used in the TPU experiment emulates an $\mathrm{ABL}$ power-law that represents a terrain category III

\footnotetext{
${ }^{2}$ http://www.wind.arch.t-kougei.ac.jp/info_center/windpressure/lowrise/g1 20200.html
}

according to the AIJ recommendations (Tamura et al. 2004). The mean speed measured at $10 \mathrm{~cm}$ of height was about $7.4 \mathrm{~m} / \mathrm{s}$ which corresponds to about $22 \mathrm{~m} / \mathrm{s}$ at a height of $10 \mathrm{~m}$ on the full scale. Therefore, at the real scale, this wind profile can be defined by parameter values: $U_{\mathrm{s}}=23.8 \mathrm{~m} / \mathrm{s}$, $z_{\mathrm{s}}=10 \mathrm{~m}$ and $\alpha=0.2$. Using these values in the Power-law module, the configuration $U_{\text {ref }}=22.41 \mathrm{~m} / \mathrm{s}, z_{\text {ref }}=9.82 \mathrm{~m}$ and $z_{0}=0.0615 \mathrm{~m}$ achieves the best fitting of the log-law to the experimental power-law. To compute $C_{p}$ values, $U_{H}=$ $18.49 \mathrm{~m} / \mathrm{s}$ is used, while an undisturbed pressure $p_{\infty}=0 \mathrm{~Pa}$ is taken in agreement with the value employed in the TPU experiment.

Figure $7(\mathrm{c})$ shows the comparison of $\overline{C_{p}}$ results obtained for each window against the experimental ones derived from the pressure taps on the corresponding window area. Note that for each wind incidence angle, the TPU database presents the entire time series of point $C_{p}$ data. So, each $C_{p}$ series is first averaged in time, and then the surface-averaged $\left(\overline{C_{p}}\right)$ on the window is calculated as an area-weighted average. Also, values of $\overline{C_{p}}$ on Surf- 2 obtained using Swami and Chandra (S\&C) equation (Swami and Chandra 1988), available by default in EnergyPlus for low-rise buildings, are plotted. This serves to analyze the common assumption of using the $\overline{C_{p}}$ value of the entire surface (wall) for all the openings (Win-1, Win-2, and Win-3) on it.

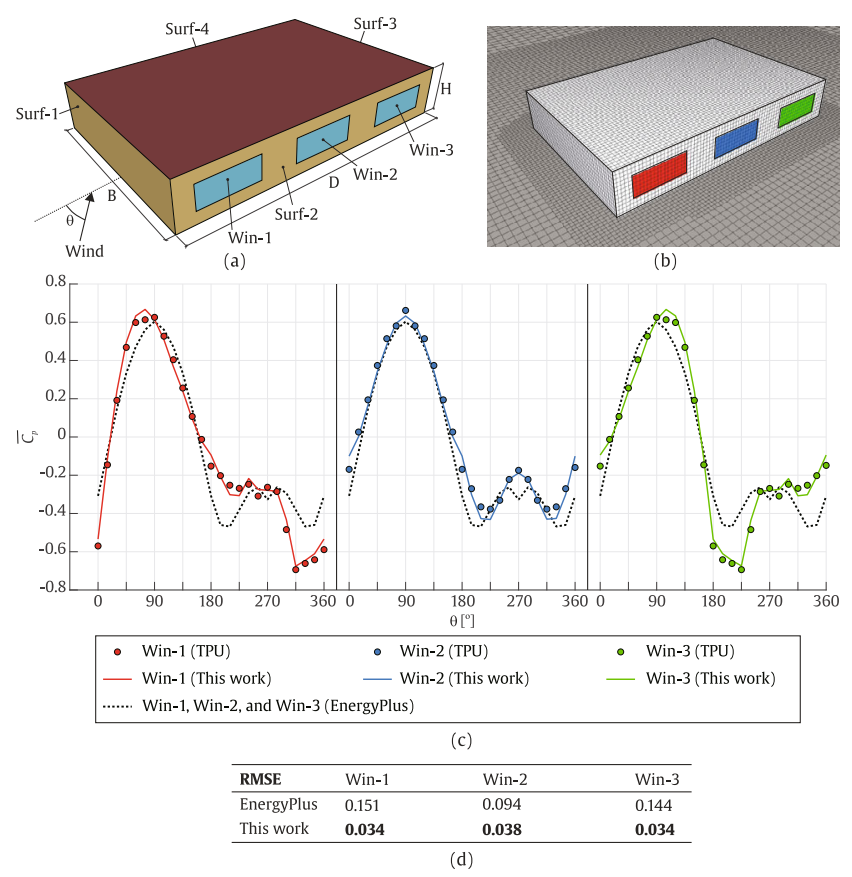

Fig. 7 Case study of a low-rise building with openings (windows): (a) the geometry model generated in the IDF file; (b) details of the resulting mesh; (c) results of $\overline{C_{p}}$ on three windows of a low-rise building, the experimental ones derived fromTPU database and the computed using the analytical S\&C equation (EnergyPlus); (d) RMSEs regarding experimental data of, both, the estimations of EnergyPlus and the results of this work 
Regarding the accuracy of $\overline{C_{p}}$ values predicted by the platform, the results show a proper agreement with the experimental data on the three windows for almost all the wind incidence angles in comparison. The largest differences, but actually small inerror magnitude, are found for $\theta=0^{\circ}$ and for the wind angles where $\overline{C_{p}}(\theta)$ presents local extrema (minimum or maximum), e.g., $\theta=75^{\circ}$ for Win-1.

For a given wind incidence angle, the $\overline{C_{p}}$ value computed on any window highly depends on its location on the surface. In particular, when lateral windows (Win-1 and Win-3) are placed in the wake just behind a separation zone $\left(\theta=0^{\circ}\right.$ and $\theta=180^{\circ}$ respectively) significant differences regarding $\overline{C_{p}}$ on the central window are observed. These variances are expected to be even wider for non-rectangular floor-plan buildings or comparing between windows with different areas. Even fora rectangular floor-plan building, EnergyPlus has considerable discrepancies on the windows located at leftor right-side of the wall (Win-1 and Win-3). An acceptable $\overline{C_{p}}$ prediction is only achieved when the window is centered (Win-2). These differences are quantitatively analyzed through the root-mean-square error (RMSE) obtained for $\overline{C_{p}}$ values on the three windows with both methods, see Figure $7(\mathrm{~d})$. The results of the platform decrease four times the RMSE error regarding EnergyPlus prediction on lateral windows, while for the central window the reduction is about 2.5 times.

Finally, using the post-processing module for IDF files, the updated file is obtained, including the objects EXTERNALNODE and WINDPRESSURECOEFFICIENTVALUES (one of them for each window), and WINDPRESSURECOEFFICIENTARRAY of the AirflowNetwork model. This updated IDF file is provided in Bre and Gimenez (2021).

\subsection{Buildings with balconies}

This case study aims to evaluate the capability of the platform to generate the model and accurately predict the $C_{p}$ values on the surfaces of a complex building with balconies. The case under consideration was originally studied by Chand et al. (1998) through a wind-tunnel experimental analysis. Later, it was replicated by Montazeri and Blocken (2013) using a dedicated CFD approach, from now on referred to as "M\&B".

The building model at experimental scale (1:30) has a breadth $B=0.6 \mathrm{~m}$, depth $D=0.25 \mathrm{~m}$, and height $H=$ $0.5 \mathrm{~m}$, resulting in the aspect ratios $D / B=0.4167$ and $H / B=$ 0.8333 . Three balconies with breadth $=0.15 \mathrm{~m}$, depth $=$ $0.05 \mathrm{~m}$ and height $=0.03 \mathrm{~m}$ are positioned at every one of the five floors except the ground floor. Wind pressures were measured along three vertical lines on the windward and leeward facade positioned in the middle of the balconies. Forty-five holes were drilled at equidistant points along each measurement line.

The geometry of the experimental scale model is generated using EnergyPlus objects through an IDF file, see Figure 8(a). The geometry of the balconies is easily reproduced using Shading objects. For this model, the resulting mesh has around 2.4 M polyhedral cells, where the $97 \%$ are hexahedrons. Figure 8(b) shows the grid on the building and the ground, where one extra level of refinement is employed around the surfaces without thickness representing the balconies.

In the experiment, the ABL speed profile was generated by a combination of three devices, vortex generators, a grid of horizontal rods, and a set of roughness elements on the floor of the test section, resulting in a vertical profile that obeys a log-law. Speed values of this profile were measured

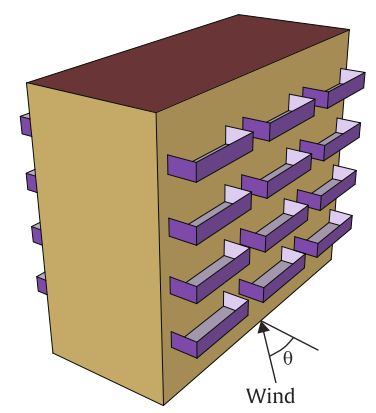

(a)

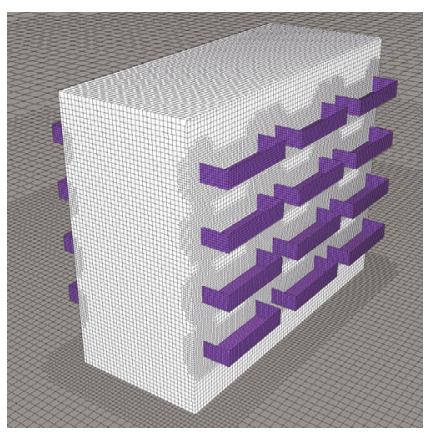

(b)

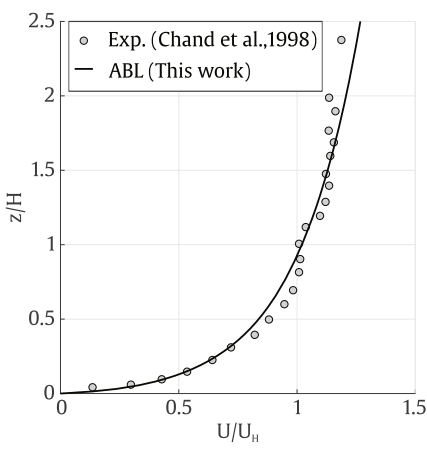

(c)

Fig. 8 Case study of a medium-rise building with balconies: (a) geometry model generated in the IDF file; (b) details of resulting mesh; (c) ABL profile obtained by fitting the experimental measurements taken from Chand et al. (1998) 
at different heights, which are used to calibrate the ABL profile through the Auto-fitting module, see Figure 8(c). The parameter values that represent the best fitting are: $U_{\text {ref }}=$ $8.7811 \mathrm{~m} / \mathrm{s}, z_{\text {ref }}=1.1158 \mathrm{~m}$, and $z_{0}=0.0123 \mathrm{~m}$. To compute $C_{p}$ values, the freestream velocity measured at the height of the building, $U_{H}=7.264 \mathrm{~m} / \mathrm{s}$ is employed, while a reference pressure $p_{\infty}=4 \mathrm{~Pa}$ is taken, which is measured at the height of the building and $0.9 \mathrm{~m}$ upstream in concordance with the experimental study.

Figure 9 shows the $C_{p}$ results for a wind incidence angle $\theta=0^{\circ}$ compared to the experimental ones (Chand et al. 1998), the ones achieved by M\&B (Montazeri and Blocken 2013) using CFD simulation with the RNG turbulence model, and the ones estimated by EnergyPlus. Regarding $C_{p}$ values obtained in this work along the vertical centerlines, a satisfactory agreement with the experimental data is observed on both windward and leeward sides, where the best fitting is achieved between the $2^{\text {nd }}$ and $4^{\text {th }}$ floors, see Figure 9(a). A similar pattern and level of accuracy is observed for the vertical lines centered on the balconies at left- and right-sides,
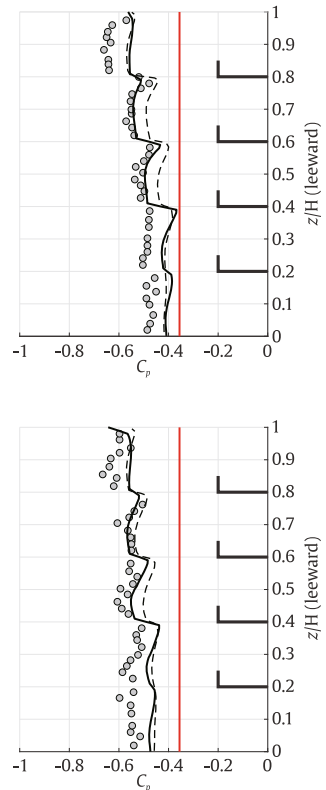

(a)
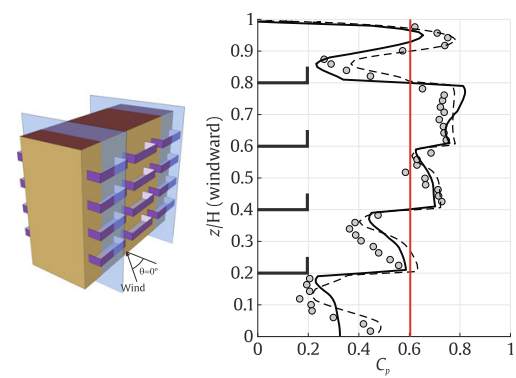

(b)

\begin{tabular}{|c|c|c|c|c|}
\hline Exp. (Chat & et. al, 1998) & EnergyPlus & CFD (M\&B) & This work \\
\hline RMSE & Leeward (center) & Windward (center) & Leeward (side) & Windward (side) \\
\hline EnergyPlus & 0.184 & 0.162 & 0.212 & 0.207 \\
\hline CFD (M\&B) & 0.073 & 0.096 & 0.076 & 0.078 \\
\hline This work & 0.063 & 0.113 & 0.062 & 0.084 \\
\hline
\end{tabular}

(c)

Fig. 9 Comparison of $C_{p}$ results for a wind incidence angle $\theta=0^{\circ}$ against the experimental ones (Exp.) reported by Chand et al. (1998), the results obtained by M\&B (Montazeri and Blocken 2013) using a dedicated CFD study, and the results estimated by EnergyPlus: (a) vertical centerlines; (b) vertical lines centered on the balconies located at left- and right-sides; (c) RMSEs of the results obtained by using the different approaches regarding the experimental reference for both windward and leeward sides, see Figure 9(b). In comparison with $\mathrm{CFD}$ results obtained by $\mathrm{M} \& \mathrm{~B}$, as expected, the accuracy is similar. The results of the platform present a slightly lower performance on the windward side, but obtain better results on the leeward side, which are particularly noticeable between the $2^{\text {nd }}$ and $4^{\text {th }}$ floors. The $C_{p}$ estimations of EnergyPlus show a poor quality on the windward side where the $C_{p}$ 's have a complex behavior because of the presence of balconies. This limitation is slightly overcome on the leeward side, however, it still has low accuracy. This comparison is quantitatively summarized in Figure 9(c) through the RMSEs. In terms of RMSE, the results from this work and the achieved by a dedicated CFD study (M\&B)have a similar and acceptable performance to predict the complex behavior of the flow on a building with balconies. Both CFD studies show RMSEs around 2.5-3 times lower than EnergyPlus for windward and leeward sides, respectively.

Figure 10 shows a similar comparison of $C_{p}$ results, but for a wind incidence angle $\theta=45^{\circ}$. Regarding $C_{p}$ values obtained on the vertical centerlines, a proper agreement is
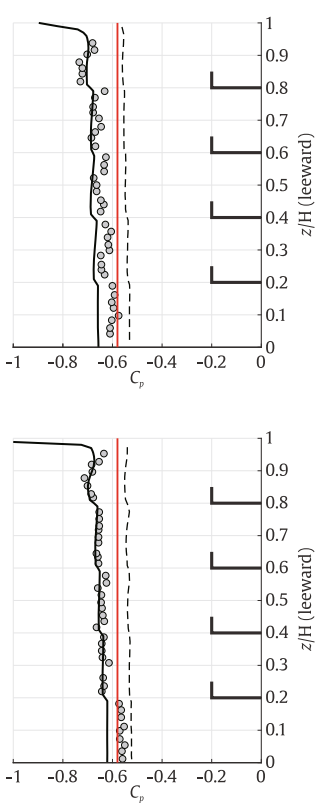

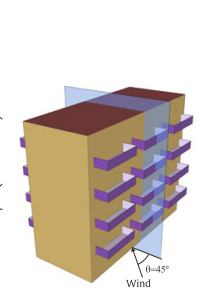

(a)

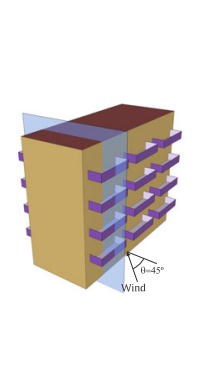

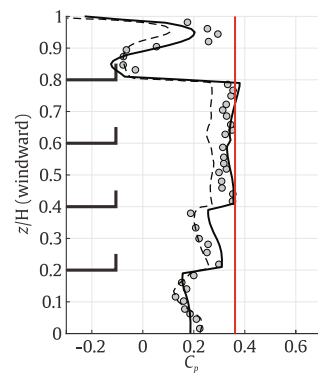

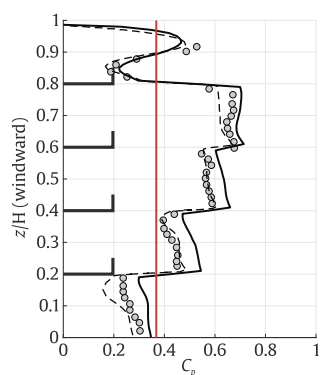

(b)

\begin{tabular}{|c|c|c|c|c|}
\hline Exp. (Char & det. al, 1998) & EnergyPlus & CFD (M\&B) & — This work \\
\hline RMSE & Leeward (center) & Windward (center) & Leeward (side) & Windward (side) \\
\hline EnergyPlus & 0.078 & 0.181 & 0.068 & (0.186 \\
\hline CFD (M\&B) & 0.107 & 0.079 & 0.104 & 0.040 \\
\hline This work & 0.041 & 0.047 & 0.030 & 0.063 \\
\hline
\end{tabular}

(c)

Fig. 10 Comparison of $C_{p}$ results for a wind incidence angle $\theta=$ $45^{\circ}$ against the experimental ones (Exp.) reported by Chand et al. (1998), the results obtained by M\&B (Montazeri and Blocken 2013) using a dedicated CFD study, and the results estimated by EnergyPlus: (a) vertical centerlines; (b) vertical lines centered on the balconies located at left- and right-sides; (c) RMSEs of the results obtained by using the different approaches regarding the experimental reference 
observed with the experimental data on both windward and leeward sides. The best agreement is, as in the $\theta=0^{\circ}$ case, achieved between the $2^{\text {nd }}$ and $4^{\text {th }}$ floors. In comparison with CFD results attained by $M \& B$, on the windward side, the results present slightly better fitting over the entire height except between $1^{\text {st }}$ and $2^{\text {nd }}$ floors. As to the leeward side, the results in this work are also slightly better at the entire height except under the $1^{\text {st }}$ floor, where both have similar accuracy, but are overestimated by the platform and underestimated by M\&B. The results achieved in this work on the lines centered in the balconies at the left-side presents a good agreement with the experimental data on the leeward side, but some considerable differences are observed on the windward side, especially between $1^{\text {st }}$ and $2^{\text {nd }}$ floors. As compared to $C F D$ results obtained by $M \& B$, on the windward side the results present a lower accuracy, but on the leeward side, the results are considerably more accurate, achieving a reliable prediction of the effects produced by the leeward balconies. Regarding the EnergyPlus estimations, despite their constant value throughout the walls, these get an enhanced fitting in terms of magnitude on the leeward side, achieving similar performance to the CFD-based ones. However, on the windward side, apart from not reproducing the behavior of $C_{p}$ 's over the potential openings behind balconies, the discrepancies are considerable in magnitude regarding the experimental values reaching RMSEs about 4 times larger than the CFD-based approaches.

Overall, the $C_{p}$ results achieved by the platform for this complex case study with balconies are accurate enough compared with the experimental ones (Chand et al. 1998). In contrast with the detailed and dedicated CFD-based analysis carried out by Montazeri and Blocken (2013), the results have a similar level of accuracy. The differences between both can be because of minor variations in the mesh, ABL speed configuration, and the value of the reference pressure $\left(p_{\infty}\right)$. However, remarkably, the herein results are obtained using an unattended procedure.

\subsection{Generic urban environment}

Urban building modeling is a rising field aiming to analyze the performance of a group of buildings, considering the correlated effects among them and attempting to close the gap between the predicted and actual performance of current buildings. Natural ventilation is a problem that spans different scales, from an urban context down to the neighborhood and the building itself. So, the behavior of natural ventilation in buildings is directly related to the actual environments that surround them.

Towards integrating actual urban environments, this section presents a detailed validation of the prediction of $C_{p}$ values on a non-isolated low-rise building in a generic urban area. This case study ${ }^{3}$ and its experimental results are taken from TPU (2021) database. The target study is a gable-roofed building with a depth-to-breadth ratio $D / B=3 / 2$, a heightto-breadth ratio $H_{0} / B=1 / 2$, and pitch roof angle $\beta=26.7^{\circ}$, see Figure 11(a). Real-scale sizes are $B=16 \mathrm{~m}, D=24 \mathrm{~m}$, and $H_{0}=12 \mathrm{~m}$, with an experimental scale of 1:100. To measure the wind pressure, over 350 taps were placed uniformly over the surfaces of the target building. The same geometry configuration is employed for the surrounding buildings, which are willing in a regular arrangement with an area density of $C_{\mathrm{A}}=0.3$, see Figures $11(\mathrm{~b})$ and (c). This area density $C_{\mathrm{A}}$ is defined as,

$$
C_{\mathrm{A}}=\frac{\text { area occupied by buildings }}{\text { area of site }}=\frac{\overline{B D}}{\overline{B^{\prime} D^{\prime}}}
$$

where, $B$ and $D$ are the breadth and depth of the buildings, respectively, $B^{\prime}$ and $D^{\prime}$ are the average distances between corresponding points on adjacent buildings in the two coordinate directions, as shown in Figure 11(c). Note that despite the regular building topologies and the "wellorganized" arrangement, this is a challenging case study because of the complexity of the flow generated along the multiple canyons.

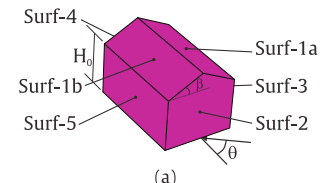

(a)

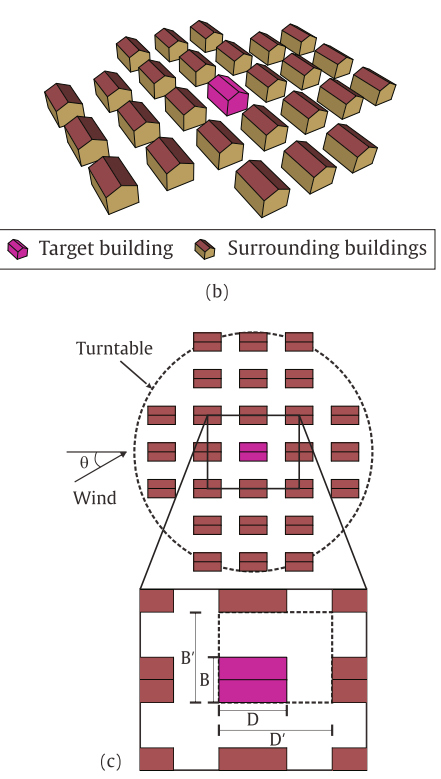

Fig. 11 Gable-roofed low-rise building in a generic urban area: (a) target building; (b) building arrangement of the case study; (c) reference of area density definition

\footnotetext{
${ }^{3}$ http://www.wind.arch.t-kougei.ac.jp/info_center/windpressure/grouplowrise/ 216616.html
} 
The wind profile used in the TPU experiment emulates an ABL power-law that represents a terrain category III according to the AIJ recommendations (Tamura et al. 2004). The mean speed measured at $10 \mathrm{~cm}$ of height was about $7.8 \mathrm{~m} / \mathrm{s}$, which corresponds to about $23.4 \mathrm{~m} / \mathrm{s}$ at a height of $10 \mathrm{~m}$ at full scale with an exponent $\alpha=0.2$. Using these in the Power-law module, $U_{\text {ref }}=23.78 \mathrm{~m} / \mathrm{s}, z_{\text {ref }}=9.86 \mathrm{~m}$, and $z_{0}=0.1208 \mathrm{~m}$ are the configuration to achieve the best agreement between the log-law and the experimental power-law. To compute $C_{p}$ values, $U_{H}=25.65 \mathrm{~m} / \mathrm{s}$ is obtained, while an undisturbed pressure $p_{\infty}=0 \mathrm{~Pa}$ is taken in concordance with the one employed in the TPU experiment.

The mesh generated by the platform has almost $3 \mathrm{M}$ polyhedral cells, where $96 \%$ of them are hexahedrons. This mesh is presented in Figure 12(a), including the details of the different levels of refinement explained in the method section.

Regarding the pressure coefficients, Figures 12(b)-(d) show the $\overline{C_{p}}$ values obtained for two walls and one roof of the target building. As can be observed from the experimental results, most of $\overline{C_{p}}$ values on the target building surfaces are negative. This is because the target building is in the

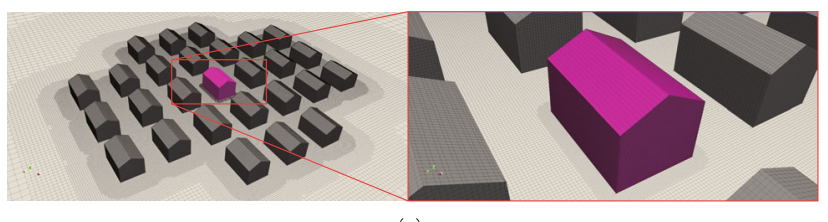

(a)
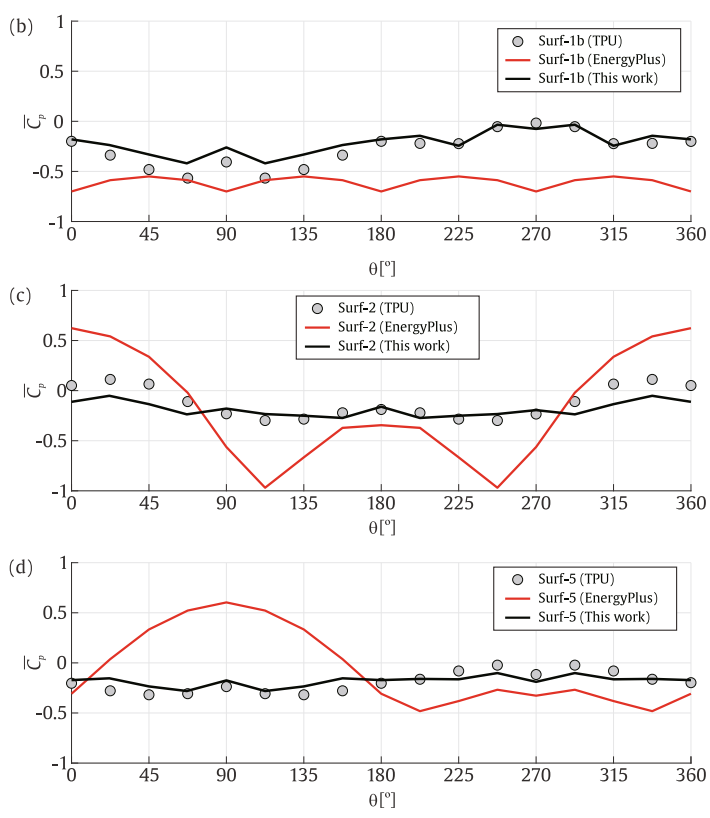

(e)

\begin{tabular}{llll}
\hline RMSE & Surf-1b & Surf-2 & Surf-5 \\
\hline EnergyPlus & 0.383 & 0.406 & 0.467 \\
This work & $\mathbf{0 . 0 9 3}$ & $\mathbf{0 . 1 1 9}$ & $\mathbf{0 . 0 7 0}$ \\
\hline
\end{tabular}

Fig. 12 Comparison results for the gable-roofed low-rise building in a generic urban area: (a) details of the resulting mesh; (b) Surf-1b; (c) Surf-2; (d) Surf-5; (e) RMSEs wake zone of other surrounding buildings for every wind incidence angle. These negative pressure regions with multiple separations of the flow resulting from the sheltered condition are well known to be the most difficult to predict using a RANS modeling approach. Despite this, the $\overline{C_{p}}$ results achieved using the standard RNG turbulence model show an acceptable agreement with the experimental ones derived from the TPU database. The results properly capture the tendencies of $\overline{C_{p}}$ regarding the wind incidence angles. The latter is an accomplished requirement to get useful data to feed natural ventilation models. Regarding EnergyPlus, except for few wind incidence angles, the estimations present large discrepancies with the experimental results. Moreover, for some surfaces (e.g. Surf-5) and wind angles $\left(0^{\circ}<\theta<\right.$ $180^{\circ}$ ), EnergyPlus predicts unphysical results, i.e. positive $\bar{C}_{p}$ values instead of negative ones.

Figure 12(e) shows the RMSEs of EnergyPlus and the results achieved by the platform for this complex case study. Besides the results properly reflect the complex physics of the flow in the generic urban arrangement, also presents an RMSE 3-4 times lower than the EnergyPlus estimations.

\subsection{High-rise building with S-shape floor-plan}

This case study aims to evaluate the capability of the platform to generate the model and accurately predict the $C_{p}$ values on the surfaces of a high-rise building with an irregular (S-shape) floor-plan. The model and the experimental results are taken from Medvecká et al. (2018), see Figure 13. The

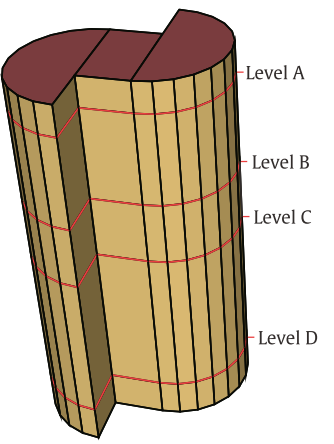

(a)

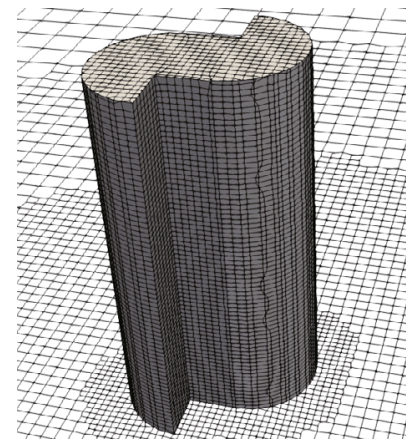

(b)

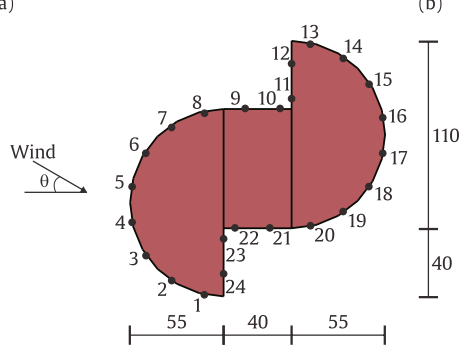

(c)

Fig. 13 High-rise model with S-shape floor-plan: (a) model and measurement levels; (b) details of the resulting mesh; (c) details of the measurement locations per level and the floor-plan dimensions 
scale of the model was 1:350. At experimental scale, the model has a breadth $B=0.15 \mathrm{~m}$, a depth $D=0.15 \mathrm{~m}$, and a height $H=0.3 \mathrm{~m}$, resulting in the aspect ratios $D / B=1$ and $H / B=2$. The experimental measurements are made at four height levels using 24 probes around the building per level, see Figure 13(c).

The wind profile employed in the experiment corresponds to a terrain between categories III and IV. So, this is modeled using the Power-law module with the configuration $U_{\text {ref }}=$ $1 \mathrm{~m} / \mathrm{s}, z_{\text {ref }}=0.3 \mathrm{~m}$ and $z_{0}=0.00233 \mathrm{~m}$.

To compute $C_{p}$ values, $U_{H}=1 \mathrm{~m} / \mathrm{s}$ is used, while an undisturbed pressure $p_{\infty}=0 \mathrm{~Pa}$ is employed in agreement with the value employed in the experiment. For this case study, the mesh has around $565 \mathrm{~K}$ polyhedral cells, where 97\% are hexahedrons, see Figure 13(b). The results for wind incidence angles of $\theta=0^{\circ}$ and $\theta=45^{\circ}$ are considered for the analysis.

Figure 14 shows the $C_{p}$ results for a wind incidence angle $\theta=0^{\circ}$ compared to the experimental ones at the four measurement levels. The predicted $C_{p}$ values properly agree with the experimental data. The largest differences are
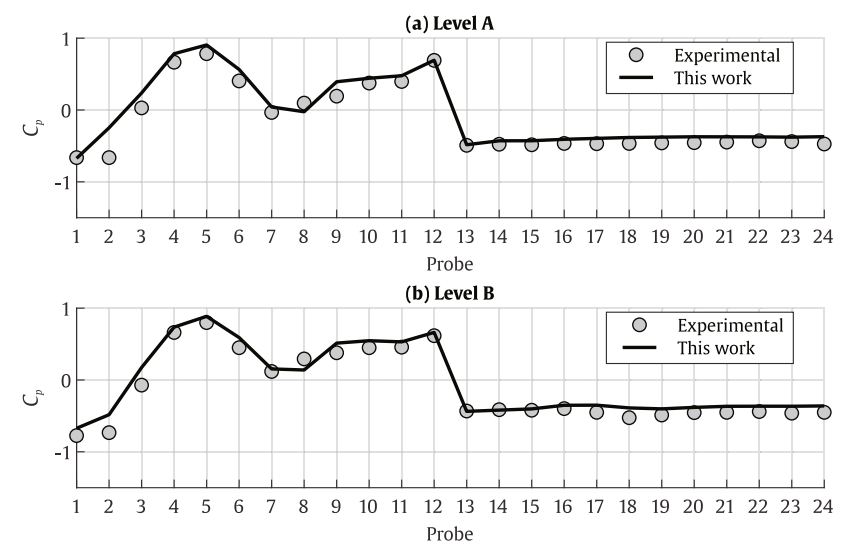

(c) Level C

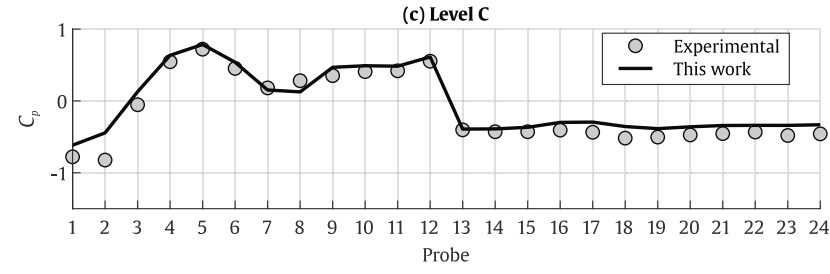

(d) Level D

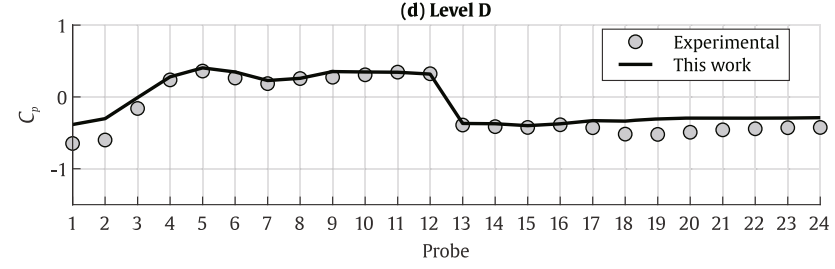

\begin{tabular}{ccccc}
\multicolumn{5}{c}{ (e) } \\
\hline & Level A & Level B & Level C & Level D \\
\hline RMSE & 0.1288 & 0.1117 & 0.1325 & 0.1318 \\
\hline
\end{tabular}

Fig. 14 Comparison of $C_{p}$ results obtained for a wind incidence angle $\theta=0^{\circ}$ against the experimental ones reported by Medvecká et al. (2018) observed in probes 1 and 2, where the highest negative values are because of the flow separation, being more noticeable at the lower levels (C and D). These deviations are related to the limited accuracy of RANS turbulence models to predict the flow in the separation region. Overall, the results show the best and the worst performance at levels B and C, with RMSEs of 0.1117 and 0.1325 , respectively.

Figure 15 shows the $C_{p}$ results predicted for a wind incidence angle of $\theta=45^{\circ}$ compared to the experimental ones. A good agreement with the experimental data is observed at the four measurement levels. As for the case of $\theta=0^{\circ}$, the largest differences are observed in probes where the highest negative values are presented after the flow separation. For this oblique wind direction, such values are in probes 13 and 14 and probes $2-4$. Overall, the results show similar performance at the four levels, with an RMSE value around 0.1318 .

\section{Discussion}

The platform provides a rich set of fully automatic tools
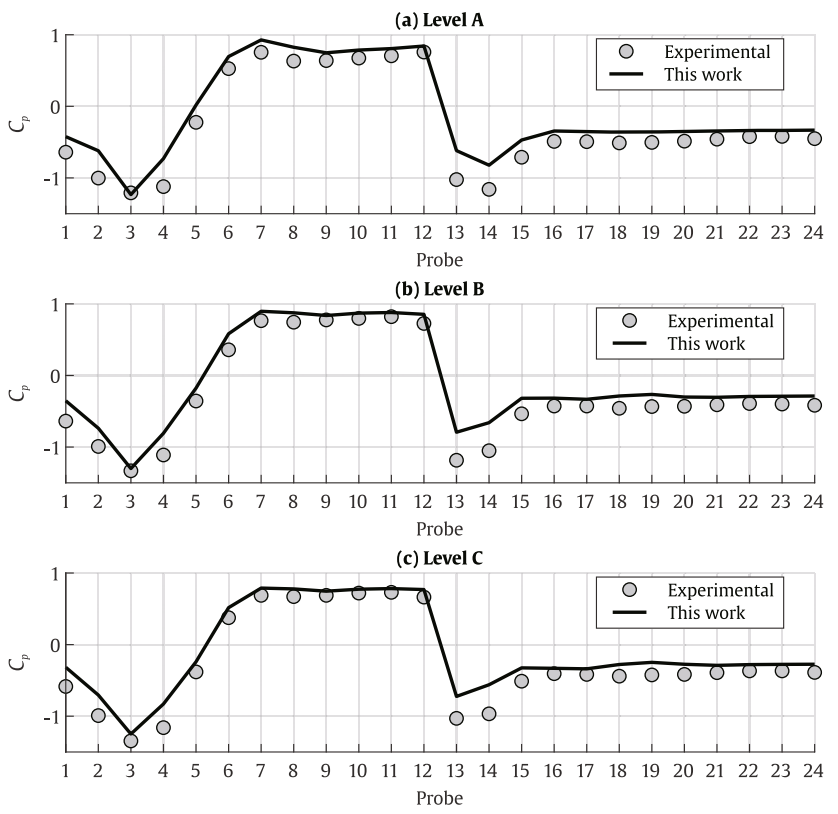

(d) Level D

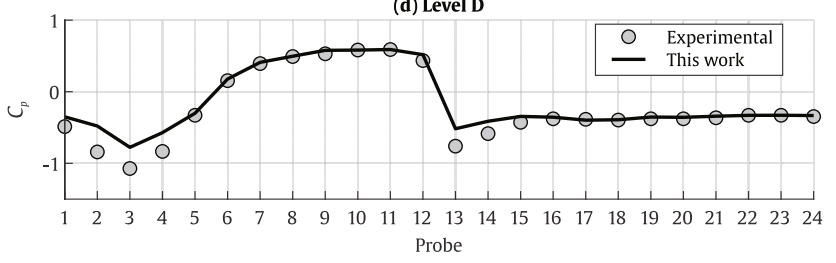

\begin{tabular}{ccccc}
\multicolumn{5}{c}{ (e) } \\
\hline & Level A & Level B & Level C & Level D \\
\hline RMSE & 0.1318 & 0.1318 & 0.1318 & 0.1315 \\
\hline
\end{tabular}

Fig. 15 Comparison of $C_{p}$ results obtained for a wind incidence angle $\theta=45^{\circ}$ against the experimental ones reported by Medvecká et al. (2018) 
and capabilities to predict wind pressure coefficients on buildings in a wide range of actual scenarios. The steady RANS modeling approach could be pointed out as a limitation to perform accurate simulations of turbulent ABL flows. However, the results obtained have shown being reliable enough for the primary aim of predicting time-averaged $C_{p}$ data to feed $\mathrm{NV}$ models. In fact, reliable results in relation to experimental ones for case studies with increasing complexity were shown through the exhaustive validation presented in this work. For these case studies, EnergyPlus showed serious limitations for predicting $C_{p}$ data, even for the simplest one which fits well within its application spectrum. It is well known that deviations on $C_{p}$ values highly influence the prediction of the air changes per hour $(\mathrm{ACH})$ driven by natural ventilation (Cóstola et al. 2010; Gimenez et al. 2018) and infiltrations (Charisi et al. 2017). Then, these large inaccuracies for the calculation of the $\mathrm{ACH}$ mean a poor prediction of the potential of energy conservation and indoor air quality. This latter application has currently a central role because its proper evaluation is mandatory to achieve the requirements demanded by the present COVID-19 global pandemic.

Regarding more complex case studies as multi-building configurations and real urban environments, the results are expected to be much closer than those achieved by parametric equations like the employed by EnergyPlus, as shown for the related case study. Users must know that RANS modeling limitations are more noticeable in these kinds of scenarios, since buildings downstream from other ones is a standard situation (Blocken et al. 2011). Despite this, even for academic and research proposes, the employment of RANS models keeps dominant, being used by $96 \%$ of the researchers (Toparlar et al. 2017) because of their outstanding balance between accuracy and computational effort.

It is worth mentioning the short computation times are required by the platform to complete a $C_{p}$ study because of its parallelized execution environment. For instance, evaluating twenty-four wind incidence angles led to a total requirement of about four hours for the isolated building studied in Section 3.1, where the simulation was carried out in a small group of five computing nodes of four cores each. This requirement was increased to only twelve hours when the sixteen wind incidence angles were analyzed in the generic urban case in Section 3.3.

The platform is growing continuously and hosts the recent advances in high-performance computing and turbulence modeling. Regarding this latter, the authors are developing and evaluating two major research lines. The first one is based on the recalibration of RANS models for particular ABL applications (Gimenez and Bre 2019), which has shown significant improvements regarding the standard ones. The second one is the very promising pseudo-DNS method based on a multi-scale approach for the full simulation of the turbulence instabilities at their different scales (Idelsohn et al. 2020, 2021). This latter methodology aims to offer the accuracy and transient behavior of LES models but the computational cost of RANS models.

\section{Limitations and future works}

Although the current status of the platform already represents a significant advance for the BPS community, it still has room for improvements and potential development areas, as is following summarized:

- Regarding input geometry formats, while the compatibility with EnergyPlus files (IDF) is fully developed, the compatibility with STL and CityGML formats should be completed. In particular, for this latter, more utilities to manage other types of sheltering objects, included in the standard, should be developed and tested. Future works also plan to incorporate the gbXML format, which is widely supported by building programs like most commercial building information modeling (BIM) software (Bracht et al. 2021)..

- The module for automatic pre-processing is in continuous evolution to manage increasingly complex case studies. In particular, new features are being developed to process and mesh geometries, where surfaces with very different length scales are simultaneously present.

- Regarding ABL modeling, the alternatives provided to configure the wind velocity profile give great versatility to meet the different levels of user needs. However, some extra features should be implemented to pursue approaching real-world applications. Among others, the incorporation and validation of the capacity to envisage topography heights as streets with sloppiness, hills, etc., as well as incorporating porous media models to better represent the sheltering effects of the vegetation, would be valuable contributions. Taking advantage of the current developments, coupling with transport models to simulate pollutants would be of interest in investigating their effect on reducing the natural ventilation potential in urban environments.

- Besides the current tools offered to predict $C_{p}$ data of a building design, the platform is also thought to host $C_{p}$ databases. These can be experimental-based or developed using the current CFD-based tools, particularly for parametric shape buildings that are commonly employed in the industry like $\mathrm{H}-, \mathrm{U}-$, L-shape, among others.

- Last, the web-based interface is a working prototype aiming to give an access point to the tools, as is shown in the method section. However, the interface developed as well as other features will be improved following the professional feedbacks received. 


\section{Conclusions}

A new cloud-based platform to predict wind pressure coefficients $\left(C_{p}\right)$ on buildings was introduced. The core of the platform comprises a set of fully automatic CFD-based tools for performing atmospheric boundary layer (ABL) simulations and obtaining detailed $C_{p}$ data. The tools can achieve results for arbitrary building shapes and surrounding environments. To reach the aim and get reliable results within the building designers' time window, a broad spectrum of novel tools was devised and developed.

The first contribution is related to the capability of processing the geometric information of the target building and its surrounding environment from different input formats (IDF, STL, and CityGML) and reconstruct this information properly in a computational wind tunnel domain. Regarding this latter, a novel shape based on a regular polygon of $P$ sides is proposed to reuse the same mesh for the several simulations required due to varying the wind incidence angle. Further, a new directional blockage ratio is derived, aiming to avoid the virtual acceleration simultaneously in horizontal and vertical directions.

Regarding the meshing procedure, a module to auto-mesh the resulting computational tunnel domain was developed. This module addresses the proper level of grid refinement and guarantees the mesh requirements recommended in the international guidelines for the best practices for the CFD simulation of flows in urban environments. The module has shown great robustness since, mostly and despite the complexity of the analyzed case, the automatic procedure achieves meshes with a large percentage of hexahedral cells. This aspect favors the quality of the numerical solution attained.

Four easy-to-configure modules to establish the horizontally homogeneous ABL wind profile were developed to address the different expertise levels and requirements of users. The first one is a straightforward module to set a wind profile based on the log-law by selecting from four types of terrains. Two modules are based on customizable log- and power-law, respectively. The latest one is to fit automatically a set of measured values using the log-law wind profile.

To achieve reliable results but within an acceptable time frame for building designers, a scheme of two-level parallelization was developed and implemented on the platform. The simulation-level addresses the partition of the computational domain and parallel simulation of a wind incidence angle, and the task-level parallelizes the required simulations over the computational resources. This feature, besides the use of a RANS modeling approach, allows users to have quick responses and dispose of several potential options during the design stage.
Above all the aforementioned contributions, remarkably, the entire workflow and the expert-CFD decisions taken in each stage are fully automatic. Within this unattended pipeline, particular and useful features to assist many building designers were developed by achieving full compatibility of the inputs and outputs with the EnergyPlus software. This means that the input geometry can be provided from the same IDF file generated to perform a building performance simulation (BPS) in EnergyPlus. Here, a valuable procedure is the auto-recognition of the openings (windows and doors) to compute the averaged pressure coefficients $\left(\overline{C_{p}}\right)$ on them. Then, the associated airflow network objects are set as outputs in an updated IDF file. Shading objects defined in the IDF to represent architectural elements of interest, such as balconies, overhangs, shadings, are considered and included in the CFD simulations.

Finally, the strengths and capabilities of the platform were tested through an exhaustive validation against wind tunnel experimental data. The case studies include buildings with openings, balconies, an irregular floor-plan, and a surrounding urban environment. The results have shown a suitable agreement with the experimental data. In the simplest case of an isolated low-rise building, the RMSE of $C_{p}$ data predicted by EnergyPlus is reduced using our platform from $60 \%$ to $77 \%$ on central and side windows, respectively. For a more complex case study of a target building surrounded by a generic arrangement of other buildings, the results can reduce the RMSE up to $85 \%$ in comparison with the EnergyPlus estimations.

Therefore, the novel platform introduced in this work has shown being a reliable $C_{p}$ data source and its development represents a significant contribution to the BPS community. We invite readers, researchers, and practitioners to test the platform in their research and projects.

\section{Data availability}

For a closer analysis or its reproduction, the results and the input geometry data used to generate them can be found at http://dx.doi.org/10.5281/zenodo.5796295.

Electronic Supplementary Material (ESM): the appendix is available in the online version of this article at https://10.1007/s12273-021-0881-9.

\section{Acknowledgements}

For funding this work, we would like to thank the Agencia Nacional de Promoción de la Investigación, el Desarrollo Tecnológico y la Innovación (Agencia I+D+i), Argentina, via the projects PICT-2018 N03252 and PICT-2018 N02464, Res. N401-19. 


\section{References}

ASHRAE (2009). ASHRAE Handbook-Fundamentals. Atlanta, GA, USA: American Society of Heating, Refrigerating and AirConditioning Engineers.

Barlow JB, Rae WH, Pope A (1999). Low-Speed Wind Tunnel Testing, 3rd edn. New York: John Wiley \& Sons.

Blocken B, Stathopoulos T, Carmeliet J, et al. (2011). Application of computational fluid dynamics in building performance simulation for the outdoor environment: an overview. Journal of Building Performance Simulation, 4: 157-184.

Blocken B (2015). Computational Fluid Dynamics for urban physics: Importance, scales, possibilities, limitations and ten tips and tricks towards accurate and reliable simulations. Building and Environment, 91: 219-245.

Blocken B (2018). LES over RANS in building simulation for outdoor and indoor applications: A foregone conclusion? Building Simulation, 11: 821-870.

Bracht MK, Melo AP, Lamberts R (2021). A metamodel for building information modeling-building energy modeling integration in early design stage. Automation in Construction, 121: 103422.

Bre F, Gimenez JM, Fachinotti VD (2018). Prediction of wind pressure coefficients on building surfaces using artificial neural networks. Energy and Buildings, 158: 1429-1441.

Bre F, Gimenez JM (2021). CpSimulator examples dataset. http://dx.doi.org/10.5281/zenodo.5796295. Accessed 22 Dec 2021.

Carrilho da Graça G, Linden P (2016). Ten questions about natural ventilation of non-domestic buildings. Building and Environment, 107: 263-273.

Chand I, Bhargava PK, Krishak NLV (1998). Effect of balconies on ventilation inducing aeromotive force on low-rise buildings. Building and Environment, 33: 385-396.

Charisi S, Waszczuk M, Thiis TK (2017). Investigation of the pressure coefficient impact on the air infiltration in buildings with respect to microclimate. Energy Procedia, 122: 637-642.

Chen Y, Tong Z, Malkawi A (2017). Investigating natural ventilation potentials across the globe: Regional and climatic variations. Building and Environment, 122: 386-396.

Cóstola D, Blocken B, Hensen JLM (2009). Overview of pressure coefficient data in building energy simulation and airflow network programs. Building and Environment, 44: 2027-2036.

Cóstola D, Blocken B, Ohba M, et al. (2010). Uncertainty in airflow rate calculations due to the use of surface-averaged pressure coefficients. Energy and Buildings, 42: 881-888.

Crawley DB, Lawrie LK, Winkelmann FC, et al. (2001). EnergyPlus: creating a new-generation building energy simulation program. Energy and Buildings, 33: 319-331.

Ding C, Lam KP (2019). Data-driven model for cross ventilation potential in high-density cities based on coupled CFD simulation and machine learning. Building and Environment, 165: 106394.

DOE (2021). ANSI/ASHRAE/IES Standard 90.1. Prototype Building Models, Secondary School. U.S. Department of Energy. Available at https://www.energycodes.gov/prototype-building-models\# Commercial. Accessed 20 Nov 2021.

Fabritius B, Tabor G (2016). Improving the quality of finite volume meshes through genetic optimisation. Engineering With Computers, 32: 425-440.

Ferziger JH, Peric M (2002). Computational Methods for Fluid Dynamics. New York: Springer Science \& Business Media.

Feustel HE (1999). COMIS-An international multizone air-flow and contaminant transport model. Energy and Buildings, 30: 3-18.

Franke J, Hirsch C, Jensen AG, et al. (2004), Recommendations on the use of CFD in predicting pedestrian wind environment. Cost Action C14.

Franke J, Hellsten A, Schlünzen KH, et al. (2007). Best Practice Guideline for the CFD simulation of flows in the urban environment. COST Action 732. Brussels: COST Office.

Gimenez JM, Bre F, Nigro NM, Fachinotti V (2018). Computational modeling of natural ventilation in low-rise non-rectangular floor-plan buildings. Building Simulation, 11: 1255-1271.

Gimenez JM, Bre F (2019). Optimization of RANS turbulence models using genetic algorithms to improve the prediction of wind pressure coefficients on low-rise buildings. Journal of Wind Engineering and Industrial Aerodynamics, 193: 103978.

Grosso M (1992). Wind pressure distribution around buildings: A parametrical model. Energy and Buildings, 18: 101-131.

Gu L (2007), Airflow network modeling in EnergyPlus. In: Proceedings of the 10th International IBPSA Building Simulation Conference, Beijing, China.

Hargreaves DM, Wright NG (2007). On the use of the k- $\varepsilon$ model in commercial CFD software to model the neutral atmospheric boundary layer. Journal of Wind Engineering and Industrial Aerodynamics, 95: 355-369.

Idelsohn S, Nigro N, Larreteguy A, et al. (2020). A pseudo-DNS method for the simulation of incompressible fluid flows with instabilities at different scales. Computational Particle Mechanics, 7: 19-40.

Idelsohn SR, Gimenez JM, Nigro NM, et al. (2021). The Pseudo-Direct Numerical Simulation method for multi-scale problems in mechanics. Computer Methods in Applied Mechanics and Engineering, 380: 113774.

IEA (2016). Key World Energy Statistics. Paris. International Energy Agency.

Jones W, Launder B (1972). The prediction of laminarization with a two-equation model of turbulence. International Journal of Heat and Mass Transfer, 15: 301-314.

Jung W, Jazizadeh F (2019). Human-in-the-loop HVAC operations: a quantitative review on occupancy, comfort, and energy-efficiency dimensions. Applied Energy, 239: 1471-1508.

Kastner P, Dogan T (2020). A cylindrical meshing methodology for annual urban computational fluid dynamics simulations. Journal of Building Performance Simulation, 13: 59-68.

Kato M, Launder BE (1993). The modeling of turbulent flow around stationary and vibrating square cylinders. In: Proceedings of the 9th symposium on Turbulent Shear Flows, Kyoto, Japan.

Knoll B, Phaff JC, de Gids WF (1997). Pressure simulation program. In: Updated of proceedings of the 16th AIVC Conference: Implementing the Results of Ventilation Research.

Liu S, Liu J, Yang Q, et al. (2014). Coupled simulation of natural ventilation and daylighting for a residential community design. Energy and Buildings, 68: 686-695. 
Liu F (2016). A thorough description of how wall functions are implemented in OpenFOAM. In: Proceedings of CFD with OpenSource Software.

Medvecká S, Ivánková O, MacÁk M, et al. (2018). Determination of pressure coefficient for a high-rise building with atypical ground plan. Civil and Environmental Engineering, 14: 138-145.

Menter FR (1994). Two-equation eddy-viscosity turbulence models for engineering applications. AIAA Journal, 32: 1598-1605.

Montazeri H, Blocken B (2013). CFD simulation of wind-induced pressure coefficients on buildings with and without balconies: Validation and sensitivity analysis. Building and Environment, 60: 137-149.

Muehleisen RT, Patrizi S (2013). A new parametric equation for the wind pressure coefficient for low-rise buildings. Energy and Buildings, 57: 245-249.

Ntinas GK, Shen X, Wang Y, et al. (2018). Evaluation of CFD turbulence models for simulating external airflow around varied building roof with wind tunnel experiment. Building Simulation, 11: $115-123$

OpenFOAM (2021). OpenFOAM. the OpenFOAM foundation. Available at https://openfoam.org/. Accessed 29 Nov 2021.

Orme M, Leksmono N (2002). AIVC Guide 5: Ventilation modelling data guide. International Energy Agency, Air Infiltration Ventilation Center.

Richards PJ, Hoxey RP (1993). Appropriate boundary conditions for computational wind engineering models using the $\mathrm{k}-\varepsilon$ turbulence model. In: Murakami S (Ed), Computational Wind Engineering 1. Oxford, UK: Elsevier.

Sakiyama NRM, Carlo JC, Frick J, et al. (2020). Perspectives of naturally ventilated buildings: A review. Renewable and Sustainable Energy Reviews, 130: 109933.

Seshat (2020). Seshat cluster. Available at http://www.cimec.org.ar/c3/ seshat/. Accessed 27 Nov 2021.

Shih TH, Liou WW, Shabbir A, et al. (1995). A new k- $\varepsilon$ eddy viscosity model for high Reynolds number turbulent flows. Computers \& Fluids, 24: 227-238.

Sorgato MJ, Melo AP, Lamberts R (2016). The effect of window opening ventilation control on residential building energy consumption. Energy and Buildings, 133: 1-13.

Spalart P, Allmaras S (1992). A one-equation turbulence model for aerodynamic flows. In: Proceedings of 30th Aerospace Sciences Meeting and Exhibit, Reno, NV, USA.

Swami MV, Chandra S (1988). Correlations for pressure distribution on buildings and calculation of natural-ventilation airflow. ASHRAE Transactions, 94(1), 243-266.

Tamura Y, Ohkuma T, Kawai H, et al. (2004). Revision of AIJ recommendations for wind loads on buildings. In: Proceedings of Structures Congress 2004: Building on the Past, Securing the Future, Nashville, TN, USA.
Tominaga Y, Mochida A, Yoshie R, et al. (2008). AIJ guidelines for practical applications of CFD to pedestrian wind environment around buildings. Journal of Wind Engineering and Industrial Aerodynamics, 96: 1749-1761.

Tominaga Y (2015). Flow around a high-rise building using steady and unsteady RANS CFD: Effect of large-scale fluctuations on the velocity statistics. Journal of Wind Engineering and Industrial Aerodynamics, 142: 93-103.

Tominaga Y, Akabayashi SI, Kitahara T, et al. (2015). Air flow around isolated gable-roof buildings with different roof pitches: Wind tunnel experiments and CFD simulations. Building and Environment, 84: 204-213.

Tong Z, Chen Y, Malkawi A, et al. (2016). Energy saving potential of natural ventilation in China: The impact of ambient air pollution. Applied Energy, 179: 660-668.

Tong Z, Chen Y, Malkawi A (2017). Estimating natural ventilation potential for high-rise buildings considering boundary layer meteorology. Applied Energy, 193: 276-286.

Toparlar Y, Blocken B, Maiheu B, et al. (2017). A review on the CFD analysis of urban microclimate. Renewable and Sustainable Energy Reviews, 80: 1613-1640.

TUP (2021). TPU Aerodynamic Database. Global Center of Excellence Program, Tokyo Polytechnic University, Tokyo, Japan. Available at http://wind.arch.t-kougei.ac.jp/system/eng/contents/code/tpu. Accessed: 27 Oct 2021.

Tsuchiya M, Murakami S, Mochida A, et al. (1997). Development of a new $\mathrm{k}-\varepsilon$ model for flow and pressure fields around bluff body. Journal of Wind Engineering and Industrial Aerodynamics, 67-68: 169-182.

Wieringa J (1992). Updating the Davenport roughness classification. Journal of Wind Engineering and Industrial Aerodynamics, 41: 357-368.

Yakhot V, Orszag SA, Thangam S, et al. (1992). Development of turbulence models for shear flows by a double expansion technique. Physics of Fluids A: Fluid Dynamics, 4: 1510-1520.

Zhai Z (2014). Computational fluid dynamics applications in green building design. In: Al-Baghdadi MARA (Ed), Computational Fluid Dynamics Applications in Green Design. International Energy and Environment Foundation (IEEF). pp. 1-22.

Zhai Z, Mankibi ME, Zoubir A (2015). Review of natural ventilation models. Energy Procedia, 78: 2700-2705.

Zhang X, Weerasuriya AU, Lu B, et al. (2020). Pedestrian-level wind environment near a super-tall building with unconventional configurations in a regular urban area. Building Simulation, 13: 439-456.

Zheng X, Montazeri H, Blocken B (2020). CFD simulations of wind flow and mean surface pressure for buildings with balconies: Comparison of RANS and LES. Building and Environment, 173: 106747. 